\title{
»[G]ebrochenen Zuständen ein ungebrochenes Weltverhältnis gegenüberzustellen« Max Reinhardts und Hugo von Hofmannsthals Theater der Stimmung
}

Wohl keine andere Zusammenarbeit zwischen einem Theaterpraktiker und einem Bühnenautor ist im deutschsprachigen Theater des 20. Jahrhunderts ähnlich kontinuierlich und fruchtbar verlaufen wie die zwischen Max Reinhardt und Hugo von Hofmannsthal. So eng verbunden ist ihr gemeinsames Wirken gewesen, dass sich kaum sagen lässt, ob Reinhardt die Theaterstücke und Stückbearbeitungen Hofmannsthals auf die Bühne gebracht hat oder ob besser, wie Wolfgang Nehring mit Blick auf »Elektra« und »Ödipus« formuliert, von »Hofmannsthals „Erneuerung der Antike für das Theater Max Reinhardts « ${ }^{1}$ die Rede sein sollte. Ihren Kulminationspunkt findet die Kooperation zweifellos in der Begründung der Salzburger Festspiele, an der Reinhardt und Hofmannsthal führend beteiligt waren. ${ }^{2}$ Wie weitreichend ihre Kooperation konzeptionell gewesen ist, ja wie sehr ihr Zusammenwirken als ein von einem gemeinsamen Leitgedanken durchdrungenes Projekt gesehen werden muss, das sich in seinen Wandlungen über die verschiedenen Werkphasen hinweg durchhält und fortentwickelt, wird vollends indes erst sichtbar, wenn man es in den Epochenzusammenhang einrückt, von dem Hofmannsthals und Reinhardts Projekt nicht nur bestimmt wurde, dessen Rahmen sie im Zuge ihrer Zusammenarbeit vielmehr wesentlich erst aufgespannt haben: denjenigen der Theatermoderne.

1 Wolfgang Nehring, "Elektra« und »Ödipus«. Hofmannsthals 'Erneuerung der Antiker für das Theater Max Reinhardts. In: Hugo von Hofmannsthal. Freundschaften und Begegnungen mit deutschen Zeitgenossen. Im Auftrag der Hugo von Hofmannsthal-Gesellschaft hg. von Ursula Renner und Gisela Bärbel Schmid. Würzburg 1991, S. 123-142.

2 Detailreich nachgezeichnet wird Hofmannsthals und Reinhardts Kooperation über die Jahrzehnte hinweg, die sie währte, von Konstanze Heininger, »Ein Traum von großer Magie«. Die Zusammenarbeit von Hugo von Hofmannsthal und Max Reinhardt. München 2015. 
Ist von der Theatermoderne die Rede, dann ist damit die Intention der vielgestaltigen Avantgardebewegungen des 20. (und frühen 21.) Jahrhunderts bezeichnet, die Grenze zwischen dem weltlichen Raum-Zeit-Kontinuum und einem ihm gegenüber distinkten rentweltlichten< Zeichenraum Bühne, wie sie sich im Horizont der Verpflichtung des Theaters auf die klassische Epistemer oder, semiologisch formuliert, das Zeichenmodell der Repräsentation etabliert hatte, ${ }^{3}$ zu revidieren. Als ein in diesem Sinne vom Gedanken einer >Verweltlichung der Bühne ${ }^{4}$ bestimmtes Projekt soll im Folgenden Hofmannsthals und Reinhardts gemeinsame Theaterarbeit sichtbar gemacht werden, wobei ihre Strategie zur Öffnung des Bühnenraums gegenüber dem weltlichen Raum-Zeit-Kontinuum als ein am Begriff der Stimmung orientierter Versuch angesprochen werden wird.

Im "Neuen Wiener Tagblatt" erscheint am 11. Mai 1900 eine Kritik zum Gastspiel des Berliner Deutschen Theaters am Deutschen Volkstheater in Wien. Dort heißt es:

Die Stimmung war eine so gute, daß man sich sogar einen Verstoß gegen eine Sitte gern gefallen ließ, mit der wir es sonst am Volkstheater sehr genau nehmen. Wir sind es sonst gewohnt, daß die Schauspieler peinlich darauf achten, niemals aus dem Rahmen zu treten, der durch die Soffitten gezogen ist. Gestern aber rannte im zweiten Akt zuerst Herr Rittner links, dann Herr Reinhardt (statt durch die Laube abzugehen) rechts im Eifer auf die Rampe hinaus bis unter den Vorhang vor, das ganze Bühnenbild zerreißend, das den Wienern so wichtig ist, und im dritten Akt waren gar zwei Sessel der Lehrer über die Linie vorgerückt. ${ }^{5}$

3 Michel Foucault spricht in "Die Ordnung der Dinge« davon, dass mit dem Wechsel von der frühneuzeitlichen Lehre von den Ähnlichkeiten hin zur klassischen Episteme das "Zeichen" aufgehört habe, »eine Gestalt der Welt zu sein". Semiologisch ist die "klassische Episteme" als das Zeitalter der Repräsentation zu bestimmen. Michel Foucault, Die Ordnung der Dinge. Zur Archäologie der Humanwissenschaften. Frankfurt a.M. ${ }^{9} 1990$, S. 92. - Im Folgenden wird wiederholt und auf verschiedene Aspekte der Zurichtung des Theaters für die klassische Episteme Bezug genommen. Zu allen diesen Aspekten siehe: Franz-Josef Deiters, Die Entweltlichung der Bühne. Zur Mediologie des Theaters der klassischen Episteme. Berlin 2015.

4 Hierzu demnächst: Franz-Josef Deiters, Verweltlichung der Bühne? Zur Mediologie des Theaters der Moderne. Berlin (in Vorbereitung für 2019).

5 Zit. nach Ambivalenzen. Max Reinhardt und Österreich. Ausgewählt, zusammengestellt und herausgegeben von Edda Fuhrich, Ulrike Dembski und Angela Eder. Wien 2004, 
Stellt man den inkriminierten Verstoß gegen die Theatersitte in den Kontext von Max Reinhardts etwa zeitgleichen Bemühungen um die Einrichtung des Kleinen Theaters, ${ }^{6}$ an dessen Gründung er 1901 in Berlin beteiligt war, so ist es wahrscheinlich, dass es sich bei besagtem Regelverstoß um weit mehr gehandelt hat als um einen im Affekt begangenen Lapsus. Im Kontext seiner programmatischen Äußerungen ist jenes »das ganze Bühnenbild zerreißend[e]« Betreten des Proszeniums vielmehr als bühnenpraktischer Ausdruck von Reinhardts Intention zu sehen, die etablierte Kommunikationssituation des Theaters zu revolutionieren. Es geht dem bis 1902 am Deutschen Theater Otto Brahms unter Vertrag stehenden Schauspieler um eine Verweltlichung der Bühne, das heißt um eine Revision der im Laufe des 18. Jahrhunderts erfolgten Ausgliederung des Zeichenraums Bühne aus dem weltlichen Raum-Zeit-Kontinuum. Dafür sprechen jedenfalls die Instruktionen zur innenarchitektonischen Gestaltung der neuen Spielstätte, die Reinhardt seinem Freund Berthold Held, einem der Gründungsdirektoren des Kleinen Theaters, am 4. August 1901 erteilt:

Von der Bühne müssen meiner Ansicht nach unbedingt Stufen ins Publikum führen. Das können wir gut brauchen und erhöht die Intimität, vielleicht an jeder Seite ein paar Stufen, worauf in der Skizze gleich Rücksicht genommen werden möge. ${ }^{7}$

Die von Reinhardt gewünschten Stufen sollen die Einheit von Bühnenund Zuschauerraum markieren; die dadurch erzielte »erhöht[e]«»Intimität«

S. 28. - Bei diesem Gastspiel ging es um eine Aufführung von Max Dreyers "Der Probekandidat«; Max Reinhardt spielte die Rolle des Oberlehrers Störmer.

6 Dieses ging aus dem Kabarett "Schall und Rauch« hervor. Das Kabarett ist in unserem Zusammenhang interessant als eine Form, die darauf angelegt ist, die Rampe zu überspielen: "Charakteristisch für diese neue Form war das so genannte Nummernprinzip, d.h. das Programm bestand aus verschiedenen kürzeren, eigenständigen Darbietungen, die - und dies war die zweite Besonderheit - durch einen Conférencier angekündigt und miteinander verbunden wurden. Darüber hinaus oblag es dem Conférencier, den Kontakt zum Publikum herzustellen, wobei sich hier ein ausgesprochen rüder Umgangston als Markenzeichen des Cabarets herausbildete«. Peter W. Marx, Max Reinhardt. Vom bürgerlichen Theater zur metropolitanen Kultur. Tübingen 2006, S. 35f. (Hervorh. im Orig.).

7 Max Reinhardt, [An Berthold Held,] 4. August 1901, Nordseebad Fanõ Dänemark Kurhaus. In: Max Reinhardt. Leben für das Theater. Briefe, Reden, Aufsätze, Interviews, Gespräche, Auszüge aus Regiebüchern. Hg. von Hugo Fetting. Berlin 1989, S. 76-82, hier S. 80 . 
bezeichnet das grundsätzlich veränderte Verhältnis zwischen Schauspielern und Zuschauern. ${ }^{8}$

Wenige Jahre früher übt sich auch Hugo von Hofmannsthal im Spiel mit der Rampe. In seinem frühen lyrischen Drama "Der Tod des Tizian«, das 1892 unter dem Pseudonym »Loris« in Stefan Georges »Blättern für die Kunst« erscheint, thematisiert Hofmannsthal das Verhältnis von Kunst und Leben. Entfaltet wird es von den Schülern Tizians vor dem Hintergrund des im Titel angekündigten Todes ihres Meisters. Dabei schreiben sie in ihrem Gespräch der Erscheinungswelt den Status eines chaotischen Rauschens und bewusstlosen Dämmerns zu, das erst vom Künstler in eine feste symbolische Ordnung überführt werde. In diesem Sinne stimmen sie die Apotheose des Meisters an: Er sei »der Dinge Bändger ${ }^{9}{ }^{9}$ derjenige, der »dem Leben Leben gab ${ }^{10}$ und Götter in das Nichts gewebt", der den "wesenlosen" Erscheinungen allererst »einen Sinn gegeben« habe. ${ }^{11}$ Der Prozess künstlerischen Schaffens wird von den Tizian-Schülern als ein Ordnungs- und Formierungsakt beschrieben, der erst erkennbar macht, was Leben ist:

Er hat uns aufgeweckt aus halber Nacht Und unsre Seelen licht und reich gemacht Und uns gewiesen, jedes Tages Fließen Und Fluten als ein Schauspiel zu genießen, Die Schönheit aller Formen zu verstehen Und unsrem eignen Leben zuzusehen. ${ }^{12}$

Im weiteren Verlauf des Dialogs wird der künstlerische Produktionsakt als ein chaotisch-ekstatisches Geschehen beschrieben. Tizian, heißt es, "phantasier[e]« ${ }^{13}$ und Tizianello, sein Sohn, führt aus: "Im Fieber malt er an dem neuen Bild, / In atemloser Hast, unheimlich, wild«. ${ }^{14}$ Die Me-

8 Zum Konzept des »intimen Theaters" vgl. Marianne Streisand, Intimität. Begriffsgeschichte und Entdeckung der "Intimität" auf dem Theater um 1900. München 2001, sowie Annette Delius, Intimes Theater. Untersuchungen zur Programmatik und Dramaturgie einer bevorzugten Theaterform der Jahrhundertwende. Kronberg/Ts. 1976.

9 GW GD I, S. 245-259, hier S. 255.

10 Ebd., S. 258.

11 Ebd., S. 255.

12 Ebd., S. 256.

13 Ebd., S. 249.

14 Ebd.

190 Franz-Josef Deiters 
taphorik der Unfassbarkeit signalisiert, dass der künstlerische Produktionsakt zur Sphäre des Lebens gehört und außerhalb der symbolischen Sphäre der Kunst liegt, die jene Paradigmata zur Verfügung stellt, in deren Horizont das Individuum seine Selbst- und Weltbezüge syntagmatisch realisiert. So erkennen sich die Schüler denn auch keineswegs im Meister, sondern in seinen Bildern. Selbst- und Welterkenntnis sind also über das Medium des Kunstwerks vermittelt. Wenn diese Überlegungen zutreffen, dann sollte der das Bühnengeschehen überwölbende und titelgebende Tod des Tizian, der als ein Moment gesteigerter künstlerischer Produktivität beschrieben wird, aber nicht, wie Peter Szondi es tut, realistisch als das physische Sterben eines menschlichen Individuums verstanden werden. ${ }^{15}$ Vielmehr allegorisiert der Tod des Tizian das Überschreiten der Schwelle zwischen Leben und Kunst, chaotischem Rauschen und symbolischer Ordnung.

Um die Markierung dieser Schwelle geht es nun aber in dem Prolog, der dem Stück vorangestellt ist. In ihm tritt die Figur des Pagen auf die Bühne, der das Stück, das zur Aufführung gelangen soll, bereits kennt ${ }^{16}$ und damit als Sprechinstanz in der Hierarchie des hofmannsthalschen Textes eine Metaebene gegenüber dem Diskurs der Tizian-Schüler besetzt. Doch andererseits besteht die Funktion dieser Figur gerade in der Transgression jener Grenzen, welche die Ebenen des Textgefüges voneinander scheiden. Der Page, heißt es, "setzt sich auf die Rampe und lä)st die Beine [...] ins Orchester hängen « ${ }^{17}$, spricht das Publikum direkt an und überschreitet damit die Grenze zwischen Bühnen- und Zuschauerraum, zwischen Kunst und Leben. Und auch die Grenze zu dem Stück, das er ankündigt, also zum Diskurs der Tizian-Schüler, transgrediert er, insofern er sich in ihm erkennt, wie ihm zuvor das Gemälde des Infanten als Medium der Selbstkonstitution dient. So sagt er über das Gemälde:

Ich seh ihm ähnlich - sagen sie - und drum

Lieb ich ihn auch und bleib dort immer stehn

Und ziehe meinen Dolch und seh ihn an

15 Peter Szondi, Das lyrische Drama des Fin de siècle. Frankfurt a.M. 21991, S. 216-251.

16 GW GD I, S. 247.

17 Ebd. (Hervorh. im Orig.) 
Und lächle trüb: denn so ist er gemalt:

Traurig und lächelnd und mit einem Dolch...$^{18}$

Und über das Stück äußert er: »Mir hats gefallen, [...] weils ähnlich ist wie ich ${ }^{19}{ }^{19}$ Auch der Prolog des hofmannsthalschen Stücks postuliert damit den medialen Status der Kunst für die Selbstkonstitution des Individuums, die sich als eine Realisierung jener Konzepte präsentiert, welche die Kunst zur Verfügung stellt. Damit wird jedoch die Hierarchie der Sprechinstanzen, wie sie im Horizont des wissenschaftlichen Wirklichkeitskonzepts zur Eindämmung der literarischen Semiose fixiert wird, eingeebnet. Überdies hat der Page das Stück, wie er verkündet, von seinem »Freund«, dem »Dichter«, erhalten. ${ }^{20}$ Insofern es sich bei dem Stück aber um den Tod des Tizian handelt, wird damit die Autorinstanz in die Fiktion hineingeholt, die sich auf der Bühne entfaltet und zu welcher der Prolog ja auch gehört. Der »Dichter" stellt eine Instanz innerhalb und außerhalb der symbolischen Ordnung dar, die sein Text formiert, und damit ein Verhältnis von gleichzeitiger Differenz und Identität, das wiederum im Text selbst thematisiert wird, wenn der Page den "Dichter" mit den Worten zitiert: "Schauspieler deiner selbstgeschaffnen Träume, / [...] ich versteh dich, o mein Zwillingsbruder «. ${ }^{21}$ Wenn der »Dichter« sich zum "Zwillingsbruder« des Pagen erklärt, der das Gemälde des Infanten imitiert, ${ }^{22}$ so bekennt der "Dichter « sich selbst per analogiam zum Schauspieler jenes Konzepts des genialischen Künstlerindividuums, das in seinem Text, im Gespräch der Tizian-Schüler, entworfen wird. Hofmannsthals frühes Stück problematisiert den medialen Status des Theaterspiels, den der Theaterpraktiker Reinhardt mit seiner Forderung nach

18 Ebd.

19 Ebd., S. 248.

20 Ebd., S. 247.

21 Ebd.

22 Vgl.

Da blieb ich stehn bei des Infanten Bild -

[...]

Ich seh ihm ähnlich - sagen sie - und drum

Lieb ich ihn auch und bleib dort immer stehn

Und ziehe meinen Dolch und seh ihn an

Und lächle trüb: denn so ist er gemalt:

Traurig und lächelnd und mit einem Dolch ...

Und wenn es ringsum still und dämmrig ist,

So träum ich dann, ich wäre der Infant,

Der längst verstorbne traurige Infant ... (Ebd.)

192 Franz-Josef Deiters 
den die Kontinuität von Bühnen- und Zuschauerraum markierenden Stufen aufwirft. Gleichzeitig thematisiert es auf der Ebene der dramatischen Konfiguration das Verhältnis von Kunst und Leben und zieht dem Diskurs damit jene epistemologische Ebene ein, die beim Theaterpraktiker Reinhardt im Hintergrund bleibt, im Werk Hofmannsthals hingegen kontinuierlich reflektiert wird. Reinhardt und Hofmannsthal begegneten sich erstmals 1900 im Rahmen eines Gastspiels des Berliner Deutschen Theaters am Deutschen Volkstheater in Wien. ${ }^{23}$

III

Um die von Reinhardt und Hofmannsthal zunächst unabhängig voneinander betriebene Revision des Verhältnisses von Bühnen- und Zuschauerraum näher zu bestimmen, ergibt es Sinn, die Stimmen der Theaterkritiker heranzuziehen, die auf Reinhardts Inszenierungen am Kleinen Theater reagieren, denn sie stecken die Grenzen des Theaterdiskurses ab. So merkt Hermann Bahr beispielsweise an, dass am Kleinen Theater unter Reinhardts Regie »jedes Stück aus der Form des Dichters erst in die des Schauspielers umgeführt " werde und dass »der Maler [...] den Ton des Schauspielers auf[nehme]« und »ihn durch seine Kunst aus[drücke].$^{24}$ Damit wird das Eigenrecht der Inszenierung gegenüber dem dramatischen Text betont. Die Transposition des Dramas vom Medium der Schrift in dasjenige des Bühnenspiels wird nicht mehr, wie im Horizont der klassischen Episteme, als eine Ausrichtung des Mediums Bühne auf dasjenige der Schrift gedacht, also nicht mehr als ein Vorgang der Entweltlichung der Bühne, sondern umgekehrt als eine Verweltlichung der »Form des Dichters«.

Einen Schritt weiter in der Beschreibung von Reinhardts Verweltlichungsstrategie geht ein anonymer Kritiker des "Deutschen Tagblatts«, wenn er Reinhardts 1903 am Deutschen Volkstheater in Wien gezeigte

23 "Der angesehene Essayist und Kulturkritiker Hermann Bahr gehörte [...] von Beginn an zu den Bewunderern Reinhardts. Im Verlaufe dieses Gastspieles vermittelte er ihm die Bekanntschaft der bedeutendsten Vertreter der Wiener Moderne - darunter Hugo von Hofmannsthal, Richard Beer-Hofmann, Alfred Roller, Kolo Moser und Otto Wagner. Im Zuge dessen entstand eine Reihe gemeinsamer Ideen, wie etwa der Plan eines Zweistädte-Theaters für Wien und Berlin«. In: Ambivalenzen (wie Anm. 5), S. 34.

24 Hermann Bahr in Neues Wiener Tagblatt, 1. Mai 1903, zit. nach Ambivalenzen (wie Anm. 5), S. 38.

Max Reinhardts und Hugo von Hofmannsthals Theater der Stimmung 193 
Inszenierung von Maurice Maeterlincks "Pelléas und Mélisande« (1893) lobt:

Immer sind es Bilderwirkungen, von denen Maeterlinck ausgeht oder auf die er zusteuert [...]. Gewiß, die szenischen Bilder, zu denen sich Maeterlincks Traumgesichte verdichtet, lösen zuweilen mächtige Stimmungen aus und sind in der Aufführung des Berliner Kleinen Theaters geeignet, uns zu zeigen, welch' reiche Stimmungsbehelfe der Bühnenkunst noch zugeführt werden können, wenn man endlich daran geht, mit der Rampenbeleuchtung zu brechen und die Bühnendekorationen auf eine neue Grundlage zu stellen. ${ }^{25}$

Wurde im Laufe des 18. Jahrhunderts sukzessive die Rampenbeleuchtung bei gleichzeitiger Verdunkelung des Zuschauerraums eingeführt, um den Ausschluss des Zeichenraums Bühne aus dem weltlichen RaumZeit-Kontinuum zu markieren, so signalisiert Reinhardts Verzicht auf die Rampenbeleuchtung den entgegengesetzten Prozess. Und auch der Effekt, der durch die veränderte Beleuchtungssituation erzielt werden soll, wird aus der Sicht des professionellen Rezipienten klar benannt: Sie erzeuge "zuweilen mächtige Stimmungen«. Damit ist ein Stichwort aufgerufen, das im Zentrum auch von Hugo Wittmanns Kritik an Reinhardts Inszenierung von Hofmannsthals »Elektra» (1904) steht:

Herr Reinhardt hat sich offenbar vor allem das Ziel gesteckt, das darzustellende Drama in einem bestimmten Gesamtton einzutauchen, das Kunstwerk der Bühne einheitlich zu grundieren. Er will Stimmung erzeugen, Stimmung und wieder Stimmung. [...] Den Sieg erringt er, jedoch nicht ohne Verluste, und einer der empfindlichsten ist es, um bloß einen Übelstand zu nennen, daß so oft die Deutlichkeit der Rede dem beschleunigten Tempo geopfert wird. [...] Was ist Deutlichkeit des Wortes - Stimmung, Stimmung! [...] Auf anderen Bühnen mag das Wort regieren, auf dieser herrscht die Stimmung. [...] Ausstattungsprunk kann ihm nicht vorgeworfen werden, er würde ihm nur die Stimmung wegblasen. ${ }^{26}$

Interessant ist an Wittmanns Ausführungen insbesondere die Entgegensetzung von »Stimmung" und »Deutlichkeit des Wortes«. Versteht man das Beharren des Kritikers auf der "Deutlichkeit des Wortes" als ein Insistieren auf der semantischen Dimension der Bühnensprache, so ist

25 -o- in: Deutsches Tagblatt, Ostdeutsche Rundschau, 8. Mai 1905, zit. nach Ambivalenzen (wie Anm. 5), S. 40.

26 Hugo Wittmann in: Neue Freie Presse, 16. Mai 1905, zit. nach Ambivalenzen (wie Anm. 5), S. 45.

194 Franz-Josef Deiters 
damit das Theatermodell der klassischen Episteme aufgerufen, das seine vollständige Ausformung in der Reflexions- und Wahrheitsdramatik der Weimarer Theaterreformer findet. Demgegenüber bezeichnet der Begriff der "Stimmung" ein präreflexives Verhältnis des Zuschauers zum Bühnengeschehen, ${ }^{27}$ das wesentlich emotionalen Charakter hat und die Dichotomie von sinnlicher und geistiger Sphäre, die für das Apriori des Theaters der klassischen Episteme konstitutiv ist, unterläuft. ${ }^{28}$

Eine Atmosphäre, ${ }^{29}$ welche die ontologische Differenz zwischen Bühnen- und Zuschauerraum aufhebt, versucht Reinhardt ab 1902 mit seinem Kleinen Theater und - nach seiner Übernahme des Deutschen Theaters im Jahre 1905 - mit der Einrichtung der Kammerspiele durch innenarchitektonische Gestaltung zu erzeugen. Durch die bereits erwähnten symbolischen Stufen zwischen Bühne und Zuschauerraum markiert, sollen Schauspieler und Zuschauer einander physisch nähergebracht werden. In »Über ein Theater, wie es mir vorschwebt« (1901) ist von einer "Art Kammermusik des Theaters ${ }^{30}$ die Rede; und auch die Ersetzung der Dekoration durch Lichteffekte (»Die Beleuchtung muß uns die Dekorationen ersetzen, auf die wir zunächst völlig verzichten wollen $\aleph^{31}$ ), die Reinhardt in einem Brief an Berthold Held vom 4. August 1901 für

27 Vgl. David Wellbery, der für Stimmungen konstatiert, »daß sie einen präreflexiven Charakter aufweisen. Die jeweilige Leistung der Stimmung vollzieht sich vorthematisch. Das ist vermutlich neben der Verschränkung von Subjektivem und Objektivem eine zweite wichtige Quelle der Faszination, die der Stimmungsbegriff seit dem 18. Jh. im Kontext ästhetischer Theoriebildung ausübt«. David Wellbery, Stimmung. In: Ästhetische Grundbegriffe. Historisches Wörterbuch in sieben Bänden. Bd.5. Hg. von Karlheinz Barck u.a. Stuttgart 2003, S. 703-733, hier S. 705.

28 In diesem Sinne urteilt auch Erika Fischer-Lichte, wenn sie davon spricht, dass Reinhardts Inszenierungen »eine spezifische Erfahrung während der Aufführung [ermöglichen], die nicht als hermeneutischer Prozess, also als Deutungs- und Verstehensprozess angemessen zu beschreiben ist, sondern als eine besondere Art sinnlicher Wahrnehmung, die zu physiologischen, affektiven, energetischen und motorischen Wirkungen führen kann, die den betreffenden [Zuschauer] im Verlauf der Aufführung auf eine Weise zu affizieren vermögen, dass er sich selbst als 'verwandelt erfährt - als in einer besonderen Atmosphäre gefangen, 'hypnotisiert<, von Lebensfreude durchdrungen und anderes mehr". Erika Fischer-Lichte, Sinne und Sensationen. Wie Max Reinhardt Theater neu erfand. In: Max Reinhardt und das deutsche Theater. Texte und Bilder aus Anlass des 100-jährigen Jubiläums seiner Direktion. Hg. von Roland Koberg, Bernd Stegemann und Henrike Thomsen. Berlin 2005, S. 13-27, hier S. 24.

29 Vgl. David Wellbery: "Stimmungen sind nicht bloß Weisen des psychischen Innenlebens, sondern auch Atmosphären, die uns umgeben«. Wellbery: Stimmung (wie Anm. 27), S. 705 .

30 Max Reinhardt, Über ein Theater, wie es mir vorschwebt. In: Max Reinhardt (wie Anm. 7), S. 73-76, hier S. 75 (Hervorh. im Orig.).

31 Reinhardt, [An Berthold Held,] 4. August 1901 (wie Anm. 7), S. 81.

Max Reinhardts und Hugo von Hofmannsthals Theater der Stimmung 195 
die Inszenierungen in der neuen Spielstätte des Kleinen Theaters avisiert, stellt einen Kunstgriff dar, mit dem die Illusion einer zweiten Welt gebrochen und die Kontinuität des Raum-Zeit-Kontinuums programmatisch markiert werden soll. Im Rahmen des kleineren Theaterraums, der die Bühne näher an das Parkett heranrückt, können die Zuschauer die Details im Minenspiel der Darsteller und damit die Schauspielerpersönlichkeit wahrnehmen, ${ }^{32}$ die es im Theater der klassischen Episteme gerade zu anästhesieren galt; umgekehrt vermögen durch die veränderte Beleuchtungssituation im Kammertheater die Darsteller ins Publikum zu blicken, sodass sich die Zuschauer zu individuieren beginnen, was im Theater der klassischen Episteme gerade vermieden werden sollte. Die Nähe, die Reinhardt zu erzeugen versucht, geht über die physische Ebene aber noch hinaus, denn die raumtechnischen Maßnahmen gehen mit solchen einher, die das etablierte institutionelle Gefüge des Theaters betreffen. So erinnert sich Reinhardt 1916 in einem Interview an die von ihm zur Jahrhundertwende verfolgte Wirkungsstrategie:

$\mathrm{Zu}$ den ersten Vorstellungen jedes Stückes lud ich eine ausgesuchte Schar von besonders kunstsinnigen, feinfühligen Menschen ein. Die Kritiker aber ließ ich draußen, weil diese, von Berufs wegen skeptisch und beim Zuschauen zugleich zur Arbeit gezwungen, sich nicht so völlig dem Geist der Empfindung hingeben konnten, den ich mir wünschte..$^{33}$

Die Verwandlung der Theatersituation von einer öffentlichen Veranstaltung in eine privat anmutende Zusammenkunft zieht nicht nur den Kunstsinn der einzelnen Besucher, sondern darüber hinaus die persönliche Bekanntschaft von Darstellern und Zuschauern ins Kalkül ${ }^{34}$ und ist dazu angetan, die für das Theater der klassischen Episteme konstitutive Unterbrechung der Interaktion zwischen den Beteiligten zu revidieren.

32 In spöttischem Ton, der die Ablehnung des »intimen Theaters" markiert, urteilt Maximilian Harden: "Wer hier nicht gar zu weit hinten sitzt, sieht die Bewegungen der Nasenflügel und Wangenmuskeln. Hat manchmal das Mißgefühl, einer Indiskretion schuldig zu werden". Maximilian Harden, Theater. In: Die Zukunft 58, 1907, S. 105-114, hier S. 113f.

33 Reinhardt über seine Kunst. Ein Interview. In: Max Reinhardt (wie Anm. 7), S. 368372, hier S. 369.

34 Die Schauspielerin Tilla Durieux bezeugt diesen Sachverhalt in ihren Memoiren: »Der Abend wurde mit großer Feierlichkeit begangen, und die roten Samtsessel trugen geschmückte Frauen in großer Toilette und Herren im Frack. Es war wie auf einer Gesellschaft in einem Privathaus. Das geistige Berlin kannte sich untereinander und versäumte keine Gelegenheit, um zu sehen und gesehen zu werden" (Tilla Durieux, Meine ersten neunzigJahre. Erinnerungen. München/Berlin 1971, S. 102).

196 Franz-Josef Deiters 
Dabei hat Reinhardts Strategie einer Intimisierung des Theaters eine völlig andere Wertigkeit als der Versuch der Naturalisten, die Theatersituation derjenigen des akademischen Hörsaals anzunähern, in dem Fallstudien präsentiert werden (Reinhardt spricht von »klinische[n] Irrsinnsstudie $[\mathrm{n}] \ll^{35}$, welche die naturalistische Bühne präsentiere). Von der gegenüber dem Naturalismus grundsätzlich anderen Stoßrichtung zeugt bereits Reinhardts Plädoyer für das Versdrama in einem Brief an Arthur Schnitzler vom 31. August 1902:

Ich glaube, [...] daß das Versdrama, bei uns von dem Schall und Rauch großer Ausstattungstheater befreit, wirklich lebendig werden kann, umso mehr als durch den Umbau unserer Bühne ein Apparat geschaffen wurde, der die feinsten, subtilsten und neuesten Wirkungen ermöglicht. ${ }^{36}$

Reinhardts Wiederentdeckung der gebundenen Rede ist auf die phonetische Dimension der Bühnensprache ausgerichtet; darin kommen Reinhardt und die Naturalisten überein. Suchen die Naturalisten mit der Orientierung der Figurenrede am Modus der Mündlichkeit indes den Anschluss der Bühne an die Erfahrungswelt des Publikums, so ist Reinhardts Plädoyer für den Vers in die entgegengesetzte Richtung orientiert; er ist auf eine Distanzierung der Bühnensprache gegenüber lebensweltlichen Sprechmodi hin abgestellt. Es steht daher in Übereinstimmung mit seiner generellen Abkehr vom Bühnennaturalismus, wie er sie in »Über ein Theater, wie es mir vorschwebt« formuliert:

Was mir vorschwebt, ist ein Theater, das den Menschen wieder Freude gibt. Das sie aus der grauen Alltagsmisére über sich selbst hinausführt in eine heitere und reine Luft der Schönheit. Ich fühle es, wie es die Menschen satt haben, im Theater immer wieder das eigene Elend wiederzufinden und wie sie sich nach helleren Farben und einem erhöhten Leben sehnen.

Das heißt nicht, daß ich auf die großen Errungenschaften der naturalistischen Schauspielkunst, auf die nie vorher erreichte Wahrheit und Echtheit verzichten will! [...] Aber ich möchte ihre Entwicklung weiterführen, [...] möchte denselben höchsten Grad von Wahrheit und Echtheit an das rein Menschliche wenden, in einer tiefen und verfeinerten Seelenkunst, und möchte das Leben auch von seiner anderen Seite zeigen als der pessimisti-

35 Zit. nach Leonhard M. Fiedler, Die Überwindung des Naturalismus auf der Bühne. Das Theater Max Reinhardts. In: Drama und Theater der Jahrhundertwende. Hg. von Dieter Kafitz. Tübingen 1991, S. 69-84, hier S. 75.

36 Max Reinhardt, [An Arthur Schnitzler,] 31. August 1902. In: Max Reinhardt (wie Anm. 7), S. 88f., hier S. 88. 
scher Verneinung, aber ebenso wahr und echt auch im Heitern und erfüllt von Farbe und Licht. ${ }^{37}$

Wenn Reinhardt bekundet, die Zuschauer »über sich selbst [...] in eine heitere und reine Luft der Schönheit [hinausführen] " zu wollen, »erfüllt von Farbe und Licht«, dann geht es ihm um die Erzeugung jener Stimmung, welche die Kritiker als für sein Theater charakteristisch hervorheben. Hinsichtlich der Bühnensprache wird dieser Effekt etwa durch die gebundene Rede erzielt, welche die Aufmerksamkeit der Zuschauer rein auf den Wohlklang der Figurenrede, also auf ihre phonetische Dimension, zu richten intendiert. Arthur Schnitzlers "Der Schleier der Beatrice« (1899), für dessen Inszenierung am Kleinen Theater Reinhardt die Zustimmung des Autors zu gewinnen hofft, ${ }^{38}$ vor allem aber die Dramen Hofmannsthals sind (ganz überwiegend) in Vers gesetzt und arbeiten damit auf der Ebene des literarischen Textes der Wirkungsstrategie zu, die Reinhardt für das Theater verfolgt. (Hofmannsthal thematisiert das Problematischwerden der semantischen Dimension der Sprache in »Ein Brief«, seinem fingierten Sendschreiben des Lord Chandos aus dem Jahre 1902). ${ }^{39}$ Die Priorisierung der phonetischen Dimension der Figurenrede, der Einsatz von Lichteffekten und die Verwendung plastischer Bühnenbilder haben die Funktion, das Bühnengeschehen zu einem synästhetischen Ganzen zu formen. Alfred Polgar hat in seiner Kritik der reinhardtschen Inszenierung von Hofmannsthals »Elektra« für die »Wiener Allgemeine Zeitung« vom 16. Mai 1905 begeistert bestätigt, wie sehr dem Regisseur die Erzeugung einer synästhetischen Totalität gelungen sei:

Die Reinhardtsche Inszenierung ist bewundernswert. Bewegung, Pose, Licht schlagen weit alle Eindrücke, die dem Hörer durch Stimmen in dieser ElektraAufführung vermittelt werden. [...] Die Darstellung verliert auch im höchsten Furor nicht ihren Rhythmus, die Menschen bewegen sich metrisch, die Posen, zu welchen sich ihre Gruppen schließen, lösen sich auf und gleiten in andere über, wie nur in einem wohlgeordneten Gedicht die poetischen

37 Reinhardt, Über ein Theater, wie es mir vorschwebt (wie Anm. 30), S. 73-76, hier S. 73.

38 Reinhardt, [An Arthur Schnitzler,] 31. August 1902 (wie Anm. 36), S. 88f.

39 GW E, S. 461-472.

198 Franz-Josef Deiters 
Bilder; Dekoration und Beleuchtung reimen auf die dramatischen Vorgänge. Eine Inszenierung in Versen. ${ }^{40}$

Wenn Reinhardt dennoch schon bald eine konzeptionelle Wende vollzieht, da seine auf die Verweltlichung der Bühne abzielende Wirkungsstrategie nicht aufgeht (»Diese Versuche endeten mit einer Enttäuschung «) $;^{41}$ wenn er etwa mit Blick auf die Gestaltung der Bühnenbilder anmerkt, dass er mit seinem Streben nach »einer Vollendung des Dekors « ${ }^{42}$ den gegenteiligen Effekt erzielt habe, den er intendiert hatte ( $(D i e$ Leute kamen, um auf meiner Bühne die echten Bäume zu betrachten; das war eine Neuerung, die sie mehr beeindruckte als die Kunst, die wir zu bieten hatten $\ll,{ }^{43}$ dann formuliert er die Einsicht, dass sein Experiment eines "intimen Theaters" bei den Zuschauern eine distanziert-beobachtende anstelle der gewünschten präreflexiven Rezeptionshaltung eines sinnlichen Schauens hervorgerufen hatte. Verantwortlich für das Scheitern seiner Wirkungsstrategie macht er die innenarchitektonische Einrichtung des "intimen Theaters«:

Ich habe das Theater immer aus der Gefangenschaft der Guckkasten-Bühne [...] befreien wollen. [...] Einmal habe ich einen Fehler gemacht. Ich setzte mein Publikum in zu bequeme Fauteuils. In Fauteuils läßt sich das Publikum etwas vormachen. ${ }^{44}$

Die Abstimmung der optischen, akustischen (und, im Falle echter Bäume, olfaktorischen) Elemente des Bühnengeschehens zu einem synästheti-

40 Alfred Polgar in: Wiener Allgemeine Zeitung, 16. Mai 1905, zit. nach Ambivalenzen (wie Anm. 5), S. 44.

41 Reinhardt über seine Kunst (wie Anm. 33), S. 369.

42 Ebd.

43 Ebd., S. 370. - Für seine Inszenierung von Shakespeares "Ein Sommernachtstraum" bringt Reinhardt echte Bäume auf die Bühne. Vgl. hierzu die seinerzeitige Schilderung des Dramaturgen am Deutschen Theater Heinz Herald: "Da streben gewaltige Baumriesen auf, wächst dichtes Moos, rinnt eine Quelle, stehen Birken schlank in den Himmel, blühen bunte Blumen, wölben sich Hügel, wächst wirres Gebüsch, steigen Nebel, steht ein uralter mächtiger Stamm quer über den Grund, weitet sich eine Lichtung. Immer neues gleitet [auf der Drehbühne] an uns vorüber, verschlingt sich eng, wächst zusammen. Immer wieder stehen wir vor unbekannten Teilen, frischen und erfrischenden Bildern und glauben, die Fülle, die Unerschöpflichkeit der Natur selber vor uns zu haben«. Heinz Herald, Ein Sommernachtstraum. In: Reinhardt und seine Bühne. Bilder von der Arbeit des Deutschen Theaters. Unter Mitarbeiterschaft von Ernst Deutsch, Gertrud Eysoldt, Carl Heine, Berthold Held, Hugo von Hofmannsthal, Arthur Kahane, Emil Ludwig, Einar Nilson und Eduard von Winterstein, hg. von Ernst Stern und Heinz Herald. Berlin 1919, S. 37-45, hier S. $38 f$.

44 Max Reinhardt, Das Theater - ein Lebensmittel nach wie vor. Ein Gespräch mit Max Reinhardt von Manfred Georg. In: Max Reinhardt (wie Anm. 7), S. 471-473, hier S. 472f. 
schen Ganzen bleibt, so Reinhardts Überlegung, so lange ohne Effekt, wie die Einrichtung des Zuschauerraums auf den Rezeptionsmodus der Reflexion angelegt ist. In ihren »bequeme[n] Fauteuils« verharren die Zuschauer in jener physisch stillgestellten, reflektierenden Haltung gegenüber den Bühnenvorgängen, wie sie sich im Zuge der Ausrichtung des Theaters auf die klassische Episteme etabliert hatte, statt sich von den Bühnenvorgängen sinnlich affizieren zu lassen. Ihre Aufmerksamkeit ist, wie im Theater der klassischen Episteme, weiterhin auf die semantische Dimension des Bühnengeschehens gerichtet; das ist gemeint, wenn Reinhardt konstatiert, dass das Publikum sich »[i]n Fauteuils [...] etwas vormachen« lasse.

\section{IV}

Um die Zuschauer in einen präreflexiven, ihre Sinnlichkeit erweckenden Rezeptionsmodus der Stimmung zu versetzen, verändert Reinhardt die Rezeptionssituation: "Das beste Publikum [...] ist das große Publikum, die allgemeine emotionelle Masse, das habe ich schließlich einsehen müssen ${ }^{45}$ Als Stätten des Theaterspiels wählt er fortan große Auditorien, sei dies die Musikfesthalle auf der Münchner Theresienhöhe, wo er 1910 Hofmannsthals »König Ödipus« (1906) zur Uraufführung bringt, der Berliner Zirkus Schumann, in dem er 1911 Hofmannsthals "Jedermann. Das Spiel vom Sterben des reichen Mannes" (1911) uraufführt, oder die 30000 Zuschauer fassende Londoner Olympia Hall, die er zum Schauplatz seiner Uraufführung von Karl Gustav Vollmoellers Pantomime "Das Mirakel« (1911) wählt. ’Masse` findet sich auch auf der Seite der an der Aufführung von Vollmoellers Pantomime Beteiligten. Insgesamt 2000 Darsteller bringt Reinhardt auf die Bühne. ${ }^{46}$ In einem anderen Interview zum »Mirakel« von 1914 heißt es:

Menschen der verschiedensten Stände und Klassen, die einander allzu fremd geworden sind, werden sich in demselben Raume zusammenfinden, und der Atem des Kunstwerks wird sie, wenn seine Darstellung gelingt, auch im Empfinden vereinen. ${ }^{47}$

45 Reinhardt über seine Kunst (wie Anm. 33), S. 369.

46 Vgl. Max Reinhardt (wie Anm. 7), S. 176.

47 Reinhardt über sein "Mirakel« und seine Zukunftspläne. Ein Interview. In: Max Reinhardt (wie Anm. 7), S. 364-368, hier S. 368.

200 Franz-Josef Deiters 
Die körperliche Nähe der Zuschauer zueinander soll, so sein Kalkül, jene entindividuierende emotionale Rezeptionshaltung hervorrufen, in der das Bühnengeschehen stimmungshaft aufgenommen und die Kontinuität von Bühnen- und Zuschauerraum hergestellt und nicht, wie im Kleinen Theater, durch Stufen lediglich symbolisch markiert wird.

Der Schaffung einer veränderten Rezeptionssituation mittels der Massierung von Publikum und Darstellern korrespondiert die Wahl des Genres Pantomime, das den Leib des Darstellers in den Mittelpunkt rückt, um die Dichotomie von Darsteller und dargestellter Figur zu nivellieren. In "Etwas über meine Methode«, einem Interview, das Reinhardt 1911 im Zuge der Vorbereitungen seiner Londoner »Mirakel«-Inszenierung gibt, schreibt er der Pantomime für sein Massentheater paradigmatischen Status zu:

Die ungeheure Arena eignet sich trefflich zur Gruppierung und Bewegung großer Massen, deren natürlicher Ausdruck, so weit der Zuschauer aus einiger Entfernung in Betracht kommt, das Pantomimische ist. Und die Pantomime ist der eigentliche Wesenszug in der Aufführung des "Wunders«. ${ }^{48}$

Das Stichwort "Aufführung des >Wunders« macht deutlich, dass dem Pantomimischen in Reinhardts Theaterkonzept eine grundsätzlich andere Funktion und Wertigkeit zukommt als bei den Naturalisten, die ebenfalls mit dem Mittel der Pantomime arbeiten..$^{49}$ Dem Schöpfer des modernen Massentheaters geht es darum, die Tradition des gestischen Leibes wiederzuerwecken, welche vor der Verpflichtung des Theaters auf das Repräsentationsmodell das Theaterspiel dominiert hatte. ${ }^{50}$ In

48 Max Reinhardt, Etwas über meine Methode. Ein Interview. In: Max Reinhardt (wie Anm. 7), S. 363f., hier S. 364.

49 Vgl. Franz-Josef Deiters, "Natur - X" auf der Bühne? Zur Mediologie des Theaters des Naturalismus. In: Weimarer Beiträge 63, 2017, H. 4, S. 509-522.

50 Vgl. die Ausführungen von Ulrike $\mathrm{Haß}$ zur Figur des Harlekins. "Harlekin«, urteilt $\mathrm{Haß}$, "mit all seinen Eigenarten bildet genau den Typus derjenigen Formulierbarkeit, die dem Ähnlichkeitsdenken entspricht. Er ist Text und Zeichen, indem er leibhaftig agiert. Seine ganze Figur besteht aus der Suche nach Ähnlichkeiten, welche er liest, indem er sich ihren abgepausten Zeichen ähnlich macht. [...] Durch Harlekins Geste schließen sich Bezeichnendes (Hand) und Bezeichnetes (Fliege) mit einer solchen Evidenz zusammen, wie dies nur im Rahmen vorversicherter Ordnungen möglich ist. [...] Die Hände sind Ohren, die Zehen sind Haare, die Fußsohle zeigt ihr Gesicht. Von diesem Gesicht kann man nicht sagen, daß es zu einer Person gehört. [...] Es wird vom gestischen Leib hervorgekehrt, der es im nächsten Moment zum Verschwinden bringt, um es an anderer Stelle wieder hervorzubringen. Der gestische Leib hat viele momenthafte Gesichter, Gesichtspunkte oder Blicke. Seine Fähigkeit, sich mit den zuhandenen Dingen zu verschwistern, scheint unendlich. Der Mimus, der den Ähnlichkeitsbeziehungen in der sichtbaren Welt dient, überläßt sich seinem gestischen Leib«. 
gleicher Weise spielt die Bühnengattung der Pantomime in Hofmannsthals Dramaturgie eine prominente Rolle: Als Beispiele von Hofmannsthals sich über die verschiedenen Werkphasen hinweg durchhaltender Arbeit an diesem Genre seien hier "Der Schüler. Pantomime in einem Aufzug" $(1901)^{51}$ und "Das fremde Mädchen" (1911) ${ }^{52}$ genannt; auch für "Das Große Salzburger Welttheater" (1922) hat er Pantomimen geschrieben..$^{53}$ Programmatisch äußert er sich an verschiedenen Stellen über die Gattung in einer Weise, die der reinhardtschen Sichtweise nicht nur entspricht, sondern gemeinsame Überlegungen reflektiert. In »Über die Pantomime« (1911) notiert er:

So tritt in reinen Gebärden die wahre Persönlichkeit ans Licht und über die Maßen reichlich wird der scheinbare Verzicht auf Individualität aufgewogen. Wir sehen einen menschlichen Leib, der sich in rhythmischem Fluß bewegt nach unendlichen Modifikationen, die in vorgezeichneten Bahnen ein innerer Genius leitet. ${ }^{54}$

Die Redeweise von den »reinen Gebärden« zielt auf die Überwindung der ontologischen Differenz von darstellendem und dargestelltem Gestus, also auf die Überwindung des Zeichenregimes der Repräsentation ab. Zudem räsoniert Hofmannsthal in seinem Text über das präreflexive Rezeptionsverhältnis zum Bühnengeschehen, in welches das Spiel der "reinen Gebärden« versetzen soll:

Wenn jeder Einzelne von den Zusehern eins wird mit dem, was sich auf der Szene bewegt, wenn jeder Einzelne in den Tänzen gleichsam wie in einem Spiegel das Bild seiner wahrsten Regungen erkennt, dann - aber nicht früher als dann - ist der Erfolg errungen. Solch ein stummes Schauspiel ist aber auch nicht weniger als eine Erfüllung jenes delphischen Gebotes: 'Erkenne dich selbst<, und die aus dem Theater nach Hause gehen, haben etwas erlebt, das erlebenswert war. ${ }^{55}$

Ulrike Haß, Das Drama des Sehens. Auge, Blick und Bühnenform. München 2005, S. 169 171 (Hervorh. im Orig.).

51 GW D VI, S. 53-66.

52 Ebd., S. 67-77.

53 Ebd., S. 215-259.

54 GW RA I., S. 504.

55 Ebd., S. 505. - Gleichsinnig verspricht sich Reinhardt von der Pantomime, dass sich "[e]in Kontakt zwischen Publikum und Darsteller ergibt [...], der ungeahnte, anonyme Wirkungen auslöst. Der Zuhörer wird in weit höherem Grade als sonst mit den Geschehnissen verbunden« (Max Reinhardt, Das Theater der Fünftausend. In: Max Reinhardt [wie Anm. 7], S. 446-447, hier S. 446).

\section{Franz-Josef Deiters}


Im Akt des sinnlichen Schauens, so das hofmannsthalsche Programm, werden Schauender und Geschautes eins. Es geht, mediologisch gesprochen, um die Nivellierung der Grenze zwischen Bühne und Parkett.

Konstitutiv für die Revision des Kommunikationssystems Theater, wie es sich im Horizont der klassischen Episteme etabliert hatte, ist in Reinhardts und Hofmannsthals programmatischen Überlegungen zum Massentheater aber nicht allein die sinnliche Erweckung des Publikums. ${ }^{56}$ Wenn die Pantomime zum paradigmatischen, wenngleich nicht alleinigen Genre erhoben wird, dann ist hiervon zuvörderst die Instanz des Schauspielers betroffen. Ausdrücklich formuliert Reinhardt das Ziel, mit dem Modell zu brechen, das vom Schauspieler das Anästhesieren der eigenen Persönlichkeit verlangt. Bereits in einem Brief an Berthold Held vom 1. Juni 1894 erklärt er: "Das Aufdrücken der eigenen Individualität. Das ist der Triumph der Schauspielkunst« «7; und 20 Jahre später, in »Von der modernen Schauspielkunst und der Arbeit des Regisseurs mit dem Schauspieler« (1915) zeigt er sich überzeugt, dass der Bruch mit dem klassischen Modell erfolgreich vollzogen worden sei:

Der Typus jenes Schauspielers, der sich proteusartig verwandelt, der unter Aufgabe seiner eigenen Persönlichkeit hurtig und selbst unkenntlich in die verschiedensten Gestalten und Masken zu schlüpfen vermag, ist wieder zurückgetreten hinter die starken Naturen, deren Glück es ist, sich selbst geben zu können [...]. Die Persönlichkeit ist das Höchste in aller Kunst [....$^{58}$

Bemerkenswert ist die Klarsicht, mit der Reinhardt das mediale Apriori identifiziert, aus dem die Forderung an den Schauspieler erfolgt, seine Persönlichkeit zu anästhesieren. Diese Forderung zurückzuweisen heißt, die Kunst des Theaters aus seiner Verpflichtung auf das geschriebene Wort zu lösen, in die Johann Christoph Gottsched sie mit seiner Leipziger Theaterreform erfolgreich gezwungen hatte. Dazu Reinhardt:

56 Hierzu Erika Fischer-Lichtes Hinweis auf die motorische Aktivierung der Zuschauer, die in Reinhardts Inszenierung der "Orestie« im Zirkus Schumann »nicht unbeweglich auf ihrem Platz sitzen bleiben und den Blick unverwandt auf einen Fixpunkt im Raum, wie die Guckkastenbühne ihn bis zu einem gewissen Grade darstellt, heften konnten. Vielmehr mussten sie sich wiederholt umdrehen bzw. Kopf und Oberkörper zu verschiedenen Seiten wenden, wenn sie nicht wichtige Ereignisse verpassen wollten« (Fischer-Lichte, Sinne und Sensationen [wie Anm. 28], S. 17f.).

57 Max Reinhardt [An Berthold Held, 1. Juni 1894.] In: Max Reinhardt (wie Anm. 7), S. 35-37, hier S. 37.

58 Max Reinhardt, Von der modernen Schauspielkunst und der Arbeit des Regisseurs mit dem Schauspieler. In: Max Reinhardt (wie Anm. 7), S. 412-422, hier S. 414. 
Freilich ist mir das Theater mehr als eine Hilfskunst anderer Künste. Es gibt nur einen Zweck des Theaters: das Theater [...]. Es sollen nicht mehr, wie in den letzten Jahrzehnten, die rein literarischen Gesichtspunkte die allein herrschenden sein. Es war so, weil Literaten das Theater beherrschten; ich bin Schauspieler, empfinde mit dem Schauspieler, und für mich ist der Schauspieler der natürliche Mittelpunkt des Theaters. ${ }^{59}$

Ausdrücklich knüpft er dabei an die Tradition an, mit der Gottsched und seine Nachfolger zu brechen bestrebt waren, weil sie ihnen im Horizont der klassischen Episteme nur als eine leere, da referenzlose Semiose erschienen war - an die Tradition der Commedia dell'Arte:

Ich kenne die spielerischen, die schöpferischen Kräfte im Schauspieler, und ich hätte manchmal nicht übel Lust, etwas von der alten Commedia dell'arte in unsere allzu disziplinierte Zeit zu retten, nur um dem Schauspieler wieder von Zeit zu Zeit die Gelegenheit zu geben, zu improvisieren und über die Stränge zu schlagen. ${ }^{60}$

Diese Promotion des Primats der Schauspielerpersönlichkeit ins Zentrum des Theaters hat indes Konsequenzen für diejenigen Techniken, die im Theater der klassischen Episteme perfektioniert worden waren, um die Persönlichkeit des Schauspielers unsichtbar zu machen - Maske und Garderobe:

Die Perücke hat längst nicht mehr die Bedeutung, die ihr einstmals zukam. Auch der Gebrauch der Schminke ist sehr reduziert, sie wird von den Herren nur wenig benützt, und die Frauen können sich auf der Bühne nicht mehr schminken, als sie dies ohnehin im Leben tun. Man wird bestimmt binnen kurzer Zeit nicht nur ohne Schminke und Perücke auskommen, sondern man wird auch - mit Ausnahme im historischen Drama - auf das Kostüm verzichten. ${ }^{61}$

Wo aber die weltliche Instanz des Schauspielers im Theater zu Wirkung und Geltung gebracht werden soll, sind radikale Konsequenzen auch für die Ausbildung der Schauspieler zu ziehen. Statt sie als ein Disziplinierungsgeschehen anzulegen, in dessen Zentrum der Erwerb von Techniken steht, die den Schauspieler zum Anästhesieren seiner Persön-

59 Reinhardt, Über ein Theater, wie es mir vorschwebt (wie Anm. 30), S. 74 (Hervorh. im Orig.).

60 Ebd.

61 Max Reinhardt, Der Schauspieler und seine Rolle. Eine Unterredung. In: Max Reinhardt (wie Anm. 7), S. 423-425, hier S. 425.

204 Franz-Josef Deiters 
lichkeit befähigen, formuliert Reinhardt das Ziel, die Persönlichkeit der Schauspieler zu kultivieren. Der Schauspielschule wird der Status einer Bildungseinrichtung zugewiesen, deren Ziel es ist, die unentwickelten Anlagen der Schauspielerpersönlichkeit zu entfalten. Dieses Programm formuliert Reinhardt mit aller Deutlichkeit 1905 in seiner »Rede zur Eröffnung der Schauspielschule des Deutschen Theaters Berlin«:

Wir wollen hier junge Menschen bilden.

Menschen, die jene drei Wände des Theaters mit ihrem Leben erfüllen sollen.

Menschen, deren Phantasie stark genug ist, ihrer Scham eine vierte Wand aufzurichten, wenn sie ihr Innerstes und Tiefstes entblößen.

Menschen, deren beflügelter Pulsschlag die Zeit verrückt, die alle Schrecken des Daseins in drei Abendstunden bannen können, die mit dem ersten Klingelzeichen zu leben beginnen und sterben, wenn der Vorhang fällt. Die so tief getroffen werden vom Worte des Dichters, daß ihr eigenes Leben erstarrt, während ein fremdes Leben in ihnen zittert und jubelt, jauchzt und schreit (nach des Schöpfers Geheiß). ${ }^{62}$

Dass die Auffassung von der Schauspielerausbildung als Bildungsgang der Schauspielerpersönlichkeit für Reinhardts Strategie einer Verweltlichung des Theaters paradigmatisch ist und über alle Brüche hinweg durchgehalten wird, bezeugen die Überlegungen, die er zehn Jahre später in "Von der modernen Schauspielkunst und der Arbeit des Regisseurs mit dem Schauspieler« (1915) anstellt. Dort lesen wir:

Wir können jedenfalls nichts besseres tun, als die uns angeborenen Eigenschaften zu entwickeln, und in der Schauspielschule, die dem Deutschen Theater angegliedert ist, bin ich nicht darauf bedacht, die Technik der Ausdrucksmittel gründlich zu lehren, sondern vor allem das Persönliche, Einzigartige in dem jungen Nachwuchs aufzuspüren und zu entfalten $\left[\ldots . .{ }^{63}\right.$

Reinhardts Konzept einer Kultivierung der Schauspielerpersönlichkeit beschränkt sich indes nicht auf den Bereich der formalen Ausbildung. Vielmehr stellt das Ziel, das Potenzial des Schauspielers zu realisieren, einen wesentlichen Aspekt der Arbeit des Regisseurs im Inszenierungsprozess dar: »Er [der Regisseur] schlüpft in jeden hinein, sucht ihn aus

62 Max Reinhardt, Rede zur Eröffnung der Schauspielschule des Deutschen Theaters Berlin. In: Max Reinhardt (wie Anm. 7), S. 411f., hier S. 411.

63 Reinhardt, Von der modernen Schauspielkunst und der Arbeit des Regisseurs (wie Anm. 58), S. 412-422, hier S. 415.

Max Reinhardts und Hugo von Hofmannsthals Theater der Stimmung 205 
sich herauszutreiben, ihn zu steigern, hier mit vielen Listen, da mit Bitten, dort mit Strenge ${ }^{64}$ An anderer Stelle benutzt Reinhardt die Metapher des Spiegels, um das Verhältnis von Regisseur und Schauspieler zu beschreiben:

Auf den Proben, die der Aufführung vorangehen, ist der Regisseur der einzige Zuhörer und Zuschauer, jener unentbehrliche Partner im Spiel. Nur daß hier die Wechselwirkung sich noch stärker, konkreter, aktiver gestaltet. Er muß feminin empfangen und zugleich maskulin befruchten können und zuletzt noch, ganz neutral, sich als Spiegel verhalten, der dem Schauspieler ein getreues Bild seiner Leistung zurückwirft. Denn der Schauspieler kann sich selbst nicht hören und sehen und da er ganz persönlich der wesentlichste Teil seines Werkes ist, kann er nicht davor zurücktreten, wie der Maler vor sein Bild, der Musiker, der Bildhauer, der Dichter vor seiner Schöpfung. ${ }^{65}$

Der Regisseur fungiert als Mäeutiker, der dem Schauspieler nicht etwa Anweisungen erteilt, sondern ihn sein eigenes Potenzial erkennen lässt. Bezeichnend ist dabei die Metaphorik, die Reinhardt wählt. 'Spiegelung bezeichnet in seinen Ausführungen nicht einen intellektuell-analytischen, sondern einen sinnlich-präreflexiven Vorgang. Der Regisseur leiht dem Schauspieler seine Sinne (Gesichts- und Gehörsinn), um ihm bei der Entfaltung seines Spiels zu helfen. In die gleiche Richtung weist die Beschreibung ihres Verhältnisses zueinander in der Metaphorik des Zeugungsaktes. Durch diesen sinnlich-präreflexiven Charakter sieht Reinhardt sein eigenes Regiekonzept vom intellektuell-analytischen Regiekonzept des Germanisten Otto Brahm unterschieden, das er mit dem Titel der »Kritik« belegt:

Kritik ist eine gefährliche, oft tödliche Waffe. Brahm hatte fast immer recht. Er war der beste, fast unfehlbare Kritiker. Aber er deprimierte. "Legen Sie großen Wert auf die Nuance? Lassen Sie sie weg.« Der Schauspieler ist ein Mondwandler. Er spaziert im Traum an gefährlichen Abgründen. ${ }^{66}$

Das Verhältnis zum Schauspieler ist indes nicht der einzige Bezugspunkt des Regisseurs für seine Inszenierungsarbeit. Vielmehr tritt der Schauspieler erst zu einem relativ späten Zeitpunkt in den Inszenierungspro-

64 Ebd., S. 420.

65 Ebd., S. 417.

66 Max Reinhardt, An der Grenze zwischen Wirklichkeit und Phantasie. Hintergründe Perspektiven. Das Regiebuch. In: Max Reinhardt (wie Anm. 7), S. 361-363, hier S. 363. 
zess ein, der von Reinhardt als ein Vorgang der Transmediation, das heißt als eine Überführung aus dem entweltlichten Medium der Schrift in dasjenige des lebendigen Leibes des Schauspielers, imaginiert wird. Bei verschiedenen Gelegenheiten hat Reinhardt die Funktionsstelle des Regisseurs ${ }^{67}$ und das Geschehen der Inszenierung als einen mehrphasigen Prozess beschrieben. Die erste Phase bildet das Studium des Dramentextes, seine semantische Erschließung. Die Tätigkeit des Regisseurs hat in dieser Phase intellektuell-analytischen Charakter: "Zuerst studiere ich das Manuskript des Autors mit der größten Sorgfalt durch, jede Einzelheit beachtend, jede Situation so weit als möglich ausarbeitend $«{ }^{68}$ An anderer Stelle beschreibt er die zweite Phase der Regiearbeit:

Ich mache mir eine ganze Partitur. Ich versuche, das Gebilde des Dichters aus der Atmosphäre seines Wollens und Fühlens für mich noch einmal zu schaffen, das besondere Gesetz seiner Architektur zu erkennen, es danach in greifbarer Scheinwirklichkeit wieder aufzubauen und alles seinem Wesen Fremde ihm fernzuhalten. Jede einzelne Szene des Dramas wird neu gestaltet, jede Bewegung der handelnden und der unter der Wirkung dieses Handelns stehenden Personen, jeder mimische Ausdruck, den die Situation erfordert, notiert. $^{69}$

Die Erstellung der Partitur, das heißt des Regiebuchs, ${ }^{70}$ als zweite Phase des Regieprozesses - Reinhardt spricht von einem "Umsetzen in die Wirklichkeit « ${ }^{71}$ - übersetzt das Drama aus der Linearität des Schrifttextes in eine Ordnung, die sich der räumlichen Ordnung der Bühne annähert. In Reinhardts Regiebüchern finden sich Kommentare zu Mimik, Gestik, Phonetik etc., kombiniert mit Skizzen zur Bühnendekoration, Beleuchtung etc. Dieser Überschritt erfolgt in der Imagination des Regisseurs, welche sich im Regiebuch objektiviert. Bezeichnend ist auch, wie Reinhardt den Bewusstseinszustand des Regisseurs in dieser zweiten Phase des Inszenierungsprozesses imaginiert. Dieser ist nicht mehr der intellek-

67 Leonhard M. Fiedler nennt Reinhardt den »erste[n] wirkliche[n] Regisseur des Theaters", das heißt den ersten Spielleiter, der für sich den Status eines gegenüber dem Dramatiker eigenständigen Künstlers reklamiert (Fiedler, Die Überwindung des Naturalismus [wie Anm. 35], S. 69-84, hier S. 69).

68 Reinhardt, Etwas über meine Methode (wie Anm. 48), S. 364.

69 Reinhardt über sein "Mirakel« (wie Anm. 47), S. 365.

70 John L. Styan schreibt Max Reinhardt die Erfindung des Regiebuchs zu. John L. Styan, Max Reinhardt. Cambridge u.a. 1982, S. 1; vgl. auch S. 73.

71 Reinhardt, Von der modernen Schauspielkunst und der Arbeit des Regisseurs (wie Anm. 58), S. 418.

Max Reinhardts und Hugo von Hofmannsthals Theater der Stimmung 207 
tuell-analytische Bewusstseinszustand der ersten Phase; die zweite Phase der Imagination wird in Metaphern des Gebärens und Träumens als ein emotional-sinnliches, impulsiv-eruptives Geschehen beschrieben:

Seine geistige Bühne bevölkert sich, füllt sich, kreißt und gebiert mit einem Zauberschlag eine neue, wundervolle Welt. [...] Mit trunkenen Augen, mit zitternden Händen, die Augen voll von sphärischer Musik, schleicht er an seinen Tisch und schreibt seine Visionen nieder, ins Buch neben die Worte, die sich mit Blut füllen. Er schreibt fieberhaft, gejagt, gehetzt, was er erlebt hat: neben jeden Satz eine Bemerkung, eine Note, einen Tonfall, und dann wie alles aussehen und wie alles klingen soll. Ein vollkommene Partitur sein Regiebuch. ${ }^{72}$

Die dritte Phase des Verweltlichungsprozesses Inszenierung ist in Reinhardts Entwurf jene, in welcher der Regisseur den Schauspielern sein Inszenierungskonzept vorstellt. Diese Phase ist wiederum vom Intellekt geprägt. Es geht darum, den Darstellern die semantische Dimension des zur Aufführung gelangenden Textes zu vermitteln:

Habe ich so diese Partitur fertig, dann beginnt die Roharbeit der Regie. Erstes Ziel muß sein: Alle Mitwirkenden verstehen zu lehren, was der Dichter will und was, um diesen Willen wirksam zu machen, an Empfindung und Effekt von jedem einzelnen und dadurch von der Masse ausgedrückt werden muß. Wissen die Menschen dann genau, worum es sich handelt und was sie auszudrücken haben, so beginnt der Weg an das zweite Ziel. Sie müssen nun lernen, mit welchen Kunstmitteln die vom Dichter verlangte Empfindung ausgedrückt und den Zuschauern mitgeteilt werden kann. ${ }^{73}$

In seinem programmatischen Text »Von der modernen Schauspielkunst und der Arbeit des Regisseurs mit dem Schauspieler« entwirft Reinhardt das Bild eines solchen ersten Probengesprächs in seiner Typik, die durch eine Asymmetrie des Verhältnisses von Regisseur und Schauspieler gekennzeichnet ist. Der Schauspieler benötigt den Regisseur, um sich zu seiner Rolle, wie sie das Regiebuch entwirft, ins Verhältnis zu setzen:

Der da vorne bleibt, beginnt zu sprechen, vorzusprechen, zu erläutern, sein Bild ein wenig zu enthüllen.

72 Ebd.

73 Reinhardt über sein "Mirakel« (wie Anm. 47), S. 365.

208 Franz-Josef Deiters 
Schweigend hört der Schauspieler zu. Sein Freund spricht, will ihm wieder was aufoktroyieren, was ihm nicht liegt.

Er bedauert, leider eine andere Auffassung zu haben.

Aha. Was denn für eine.

Nun kommt ein Schwall törichter Worte. Sie werden höflich angehört. Das irritiert ihn, er bleibt stecken, zuckt verlegen die Achseln.

Ein anderer zeigt sich dankbarer, beflissener, es ist zufällig der, der die große Rolle hat.

Er erkennt freudig, daß sein eigenes Wesen da aufgebaut ist, daß die Sache aus ihm heraus gedacht ist. Ein glückliches Lachen steckt ihm in der Kehle, kitzelt ihn in der Nase. Kinder, Kinder! Ein Fußbreit gewonnen. Hoffnung keimt auf. Er nimmt einen Anlauf, wird wärmer, den Einen überredet, den Anderen zwingt er, den Mißvergnügten überzeugt er von der Wichtigkeit der verachteten Rolle. Dem Vierten geht von selbst langsam ein Licht auf. ${ }^{74}$

Zum Verweltlichungsvorgang Inszenierung gehört schließlich ein weiterer Aspekt - derjenige der Aktualisierung historischer Texte und ihrer Aufführungsweisen. An verschiedenen Stellen erweist sich Reinhardt als ein Gegner dessen, was in der Musik später als historische Aufführungspraxis bezeichnet worden ist: ${ }^{.5}$

Zuerst empfängt er die Dichtung bei sich zu Hause, im stillen Kämmerlein. Voll Andacht und mit inbrünstiger Liebe gibt er sich restlos dem Werke hin und lauscht auf jedes Wort und auch auf das, was hinter den Worten steht. Er versetzt sich ganz in die Zeit des Dichters und bleibt dabei doch ein Kind seiner eigenen Zeit, unbewußt mit ihren Kräften erfüllt (ein Instrument, das der Tag gebaut hat). Gleichwohl können sich auf seinen Seiten tausendjährige Werke wie die antiken Dramen beleben. Denn das ist unser Beruf: die Werke, die wir geerbt haben, immer wieder von Neuem zu erwerben, um sie zu besitzen. Das heißt: sie aus dem Geiste unserer Zeit wieder neu zu gebären. ${ }^{76}$

In Reinhardts Projekt einer Verweltlichung der Bühne kommt dem Regisseur eine Schlüsselposition zu. Daher verwundert es nicht wenig, auf Äußerungen aus seinem Munde zu stoßen, die das Verschwinden dieser Instanz prophezeien oder dieses doch immerhin zum programmatischen Ziel erheben: "Wenn ich vom Theater der Zukunft spreche«, bekundet er 1928 in "Das ideale Theater", "möchte ich vor allem einmal feststel-

74 Reinhardt, Von der modernen Schauspielkunst und der Arbeit des Regisseurs (wie Anm. 58), S. 420.

75 Vgl. Peter Reidemeister, Historische Aufführungspraxis. Darmstadt 1996.

76 Reinhardt, Von der modernen Schauspielkunst und der Arbeit des Regisseurs (wie Anm. 58), S. 417f. (Hervorh. im Orig.). 
len, daß ich den Regisseur für eine provisorische oder besser vorübergehende Erscheinung in der Weiterentwicklung des Theaters halte «. ${ }^{77}$ Die vorübergehende Notwendigkeit dieser Verweltlichungsinstanz sieht Reinhardt dem Sachverhalt der Literarisierung des Theaters geschuldet, also seiner Verpflichtung auf das geschriebene Wort, das seinem Wesen nach ein Medium der Entweltlichung ist. »Wenn der Regisseur heutzutage nötig ist, um die Kluft, die zwischen den Autoren und den Interpreten ihrer Werke gähnt, zu überbrücken«, führt er seine oben zitierten Sätze fort, "so ist das ganz einfach eine Folgeerscheinung der traurigen Tatsache, daß die Bühnenschriftsteller ihr Handwerk nicht verstehen. Sie schreiben ihre Werke in der Einsamkeit ihrer Studierstuben «. ${ }^{78}$ Reinhardts Diagnose ist klar: Die Instanz des Regisseurs hat ihren Ort allein in einem auf das weltlose Medium Schrift verpflichteten Theater, das heißt in einem Theater, das sich immer noch im Horizont der klassischen Episteme bewegt. Im von ihm avisierten »idealen« Theater hingegen, das kein Theater der Repräsentation mehr wäre, verlöre der Regisseur seine Funktion. Reinhardt zielt auf einen mediologischen Paradigmenwechsel ab, wenn er den Bühnenautoren aufgibt, sich "von dem festeingewurzelten Vorurteil [zu] befreien, daß es unter ihrer Würde ist, für das spezifische Talent eines gewissen Schauspielers eine allein für ihn bestimmte Rolle zu schreiben « ${ }^{79}$. Die geforderte Ausrichtung des Bühnenschriftstellers an der Instanz des Schauspielers (»Den idealen Zustand hätten wir meiner Ansicht nach dann erreicht, wenn der Bühnenautor auch Schauspieler wäre ${ }^{80}$ ) intendiert die Paradigmatisierung der Instanz der leiblichen Schauspielerpersönlichkeit, und sie impliziert die Proklamation eines verweltlichten Theaters zum Leitmedium, wohingegen der im Medium der Schrift vorliegende Dramentext, und mit ihm sein Urheber, seinen angestammten paradigmatischen Status einbüßt. Das Theater der Zukunft, wie Reinhardt es vorschwebt, wird ein verweltlichtes Schauspielertheater sein, nicht mehr ein entweltlichtes Autorentheater. Wenn er Shakespeare und Molière dafür lobt, dass sie »ihre Stücke erst im Verlauf der Proben richtig wachsen und gegenständlich werden« lie-

77 Max Reinhardt, Über das ideale Theater. In: Max Reinhardt (wie Anm. 7), S. 463-467, hier S. 463.

78 Ebd., S. 464.

79 Ebd.

80 Ebd., S. 463 (Hervorh. im Orig.).

210 Franz-Josef Deiters 
ßen und "sie den Bedingungen des Theaters, für das sie sie inszenierten, und vor allem den mitwirkenden Schauspielern mit großem Geschick « ${ }^{81}$ angepasst hätten (»Die Hauptsache ist, daß die Dichtungen dieser beiden großen Dramatiker für das Theater geschrieben wurden und oft erst auf der Bühne entstanden«) ${ }^{82}$ dann sieht er ihre Vorbildfunktion darin, dass sie gerade keine Vertreter des Repräsentationszeitalters auf der Bühne gewesen sind. Seine Forderung nach Entparadigmatisierung des Autors und seiner Eingliederung in das Ensemble der Theaterkünstler korrespondiert dabei mit der Errichtung des Theaters für die Massen. Nicht nur auf der Seite der Rezeption, auch auf derjenigen der Produktion wird ein Prozess der entindividuierenden Kollektivierung erstrebt. Die Position des vereinzelten Autors soll in gleicher Weise überwunden werden wie die Vereinzelung des Zuschauers im Massentheater.

Konstanze Heininger hat angemerkt, dass Hugo von Hofmannsthal diesem weltlichen Konzept des Theaterschriftstellers bereits vor seiner Begegnung mit Max Reinhardt entsprach:

Der 'Elis im Fragment "Das Bergwerk zu Falun« war inspiriert von Josef Kainz. Im Laufe seiner dramatischen Arbeit der folgenden Jahre entstanden viele weitere Rollen für bestimmte Schauspieler - die Titelrolle in "Elektra«, der 'Schwertträger des Kreon< in »Ödipus und die Sphinx" und die 'Werkes im "Jedermann« für Gertrud Eysoldt, der 'Theodor im "Unbestechlichen" und der 'Theophik im Ballett »Prima Ballerina« für Max Pallenberg, zuletzt der sSigismund im »Turm« für Alexander Moissi. ${ }^{83}$

Aber noch ein anderer Aspekt ist für das Konzept eines weltlichen Theaterschriftstellers wesentlich: die Aufgabe nämlich des Anspruchs, Originalstücke zu verfassen, mithin einen Bruch zu vollziehen mit jenem emphatischen Konzept von Autorschaft, wie es sich im Horizont der klassischen Episteme herausgebildet hatte. Statt Dramen zu verfassen, für die er die alleinige Urheberschaft reklamieren kann, bearbeitet Hofmannsthal Werke des europäischen Kanons: Sophokles' "Elektra" (um 413) und "König Ödipus" (ca. 429-425) oder Pedro Calderón de la Barcas "Das große Welttheater« (1655; Hofmannsthal: »Das Salzburger Große Welttheater«, 1922) und »Das Leben ein Traum« (1636, Hof-

81 Ebd.

82 Ebd., S. 464.

83 Heininger, "Ein Traum von großer Magie» (wie Anm. 2), S. 104.

Max Reinhardts und Hugo von Hofmannsthals Theater der Stimmung 211 
mannsthal: "Der Turm«, 1927), um nur die bekanntesten zu nennen. Programmatisch heißt es hierzu in seinem »Wiener Brief [III] (1923): "[D]as scheint mir das eigentliche Schicksal des Künstlers: sich selber als den Ausdruck einer in weite Vergangenheit zurückführenden Pluralität zu fühlen« ${ }^{84}$ und auch in »Das alte Spiel von Jedermann« (1911) schreibt Hofmannsthal sich die Rolle eines Sachwalters der Tradition zu:

Die deutschen Hausmärchen, pflegt man zu sagen, haben keinen Verfasser. Sie wurden von Mund zu Mund weitergegeben, bis am Ende langer Zeiten, als Gefahr war, sie könnten vergessen werden oder durch Abänderungen und Zutaten ihr wahres Gesicht verlieren, zwei Männer sie endgültig aufschrieben. Als ein solches Märchen mag man auch die Geschichte von Jedermanns Ladung vor Gottes Richterstuhl ansehen. ${ }^{85}$

Zugleich jedoch setzt er sich von dem mit den Namen Johann Gottfried Herder, ${ }^{86}$ Jacob und Wilhelm Grimm, Clemens Brentano, Achim von Arnim und Joseph Görres verbundenen Projekt einer Rettung der mündlichen Traditionsbestände mittels ihrer Verschriftlichung ab, wenn er die Überführung ins Medium der Schrift als ein Verschüttungs- und Verlustgeschehen bezeichnet: "Alle diese Aufschreibungen stehen nicht in jenem Besitz, den man als den lebendigen des deutschen Volkes bezeichnen kann, sondern sie treiben im toten Wasser des gelehrten Besitzstandes ${ }^{87}$ Hat die Überführung der mündlichen Überlieferungen in die Schrift als dem paradigmatischen Medium des Repräsentationszeitalters in den Verlust dieser weltlich-kontextuellen Wissensbestände gemündet, so zielt Hofmannsthals Credo, mit dem »Jedermann« »dem deutschen Repertorium nicht so sehr etwas gegeben, als ihm etwas $z u$ rückgegeben zu haben « ${ }^{88}$ in die entgegengesetzte Richtung. Hofmannsthal sucht solche Bestände der dramatischen Tradition auf, die vor der Wende des Theaters zur klassischen Episteme entstanden sind und einem vorklassischen Zeichenregime zugehören. Waren sie im Horizont der klassischen Episteme aus dem Kanon ausgeschlossen worden, weil

84 GW RA II, S. 289.

85 GW D III, S. 89.

$86 \mathrm{Zu}$ Johann Gottfried Herders Konzept des Dichters als Stimme des Volkes vgl. FranzJosef Deiters, Auf dem Schauplatz des »Volkes«. Strategien der Selbstzuschreibung intellektueller Identität von Herder bis Büchner und darüber hinaus. Freiburg i.Br./Berlin/Wien 2006, S. 35-61.

87 GW D III, S. 89.

88 Ebd., S. 104 (Hervorh. im Orig.).

\section{Franz-Josef Deiters}


sie aus repräsentationslogischer Perspektive ein referenzloses Spiel leerer Signifikanten darstellten, so knüpft Hofmannsthal an sie an, um das klassische Zeichenregime der Repräsentation zu überwinden: "Es ist die Gefahr und der Ruhm unserer Zeit, an deren Schwelle der greise Ibsen steht, daß wir weit genug wiederum sind, uns im Allegorischen bewähren zu müssen", urteilt er 1911 in "Das alte Spiel von Jedermann ${ }^{89}$ Das Stichwort des Allegorischen ist in diesem Zusammenhang insofern wichtig, als die allegorische Darstellung die das Repräsentationsmodell steuernden Dichotomien von innen/außen, sinnlich/intelligibel unterminiert. ${ }^{90}$

Hofmannsthals semioarchäologische ${ }^{91}$ Strategie intendiert aber nicht allein, solche im Horizont der klassischen Episteme vom Kanon ausgeschlossenen Dramenbestände wiederzugewinnen. Seine Suche gilt überdies den Spuren, die eine Kontinuität des scheinbar Verlorenen bis in die Gegenwart hinein bezeugen:

Als im achtzehnten Jahrhundert, am meisten durch Lessings kraftvolle aber einseitige Bemühungen, das Theater der Gebildeten entstand, welches ganz andere, fremde Fundamente hatte und ganz neue unvolksmäßige Forderungen aufstellte, sanken die alten theatralischen Instinkte ins dumpfere Volk zurück. Aber da von diesem immer neue Elemente ins "Publikum» aufstiegen, konnte sich doch in der anerkannten theatralischen Hauptstadt Wien, mindestens in ihren Vorstädten, ein volksmäßiges Theater halten, von welchem Raimunds und Nestroys Hervorbringungen die letzten Blüten waren. ${ }^{92}$

Seine semioarchäologische Kontinuitätsthese versucht Hofmannsthal noch weiter zu erhärten, wenn er selbst in den Dramenbeständen des Rezeptionszeitalters Spuren des vorklassischen Zeichenregimes ausmacht:

Die im Volksgeschmack verborgenen Instinkte hatten auch die Kraft, in das Schaffen unserer Klassiker hineinzudringen und sich dort in so fremder Sphäre gleichsam wie im Traum geltend zu machen: so ist von Schillers »Räubern« das Hauptmotiv selber, die Verherrlichung der Räuberbande, aus der glei-

89 Ebd., S. 90.

90 Wiebke Freytag, Art. "Allegorie, Allegorese«. In: Historisches Wörterbuch der Rhetorik. Hg. von Gert Ueding. Bd. 1. Tübingen 1992, Sp. 330-392, hier Sp. 341-349.

91 Max Reinhardt verwendet den Begriff der Archäologie explizit, wenn er hinsichtlich seiner Methode gegenüber einem Londoner Journalisten erklärt: »Neben anderen Dingen will ich den größten Wert auf die archäologische Genauigkeit legen« (Reinhardt, Etwas über meine Methode [wie Anm. 48], S. 364).

92 GW D III, S. 170f. 
chen Wurzel wie so manches Drama eines reisenden Puppentheaters, das dem »bayrischen Hiask oder den "Grask verherrlicht; desgleichen die so wichtigen astrologischen Elemente im »Wallenstein« oder die Geistererscheinungen und Zaubereien in der »Jungfrau von Orleans«; vom »Faust« aber, wie der erste Teil dem Puppenspiel und dem Hans Sachs seine wesentliche Form verdankt, so sind in den zweiten unzählige Elemente der volksmäßigen Bühne, der Maskenspieltradition und endlich gar noch der Mysterienbühne hineingenommen. ${ }^{93}$

Lassen sich damit selbst die Dramenbestände des Repräsentationszeitalters in Hofmannsthals Projekt einer Verweltlichung des Theaters integrieren, so lesen sich seine Äußerungen aus dem Jahre 1922 wie eine Konkretisierung von Reinhardts 20 Jahre zuvor erhobener antihistoristischer Forderung nach Aktualisierung der kanonischen Werke: »Man muß die Klassiker neu spielen; man muß sie so spielen, wie wenn es Dichter von heute, ihre Werke Leben von heute wären «. ${ }^{94}$

Das auf Ähnlichkeitsbeziehungen abgestellte Zeichenregime eines weltlichen Theaters, wie es Hofmannsthal vorschwebt, ist dabei wesentlich zirkulär. Was im theatralen Spiel sichtbar gemacht werden soll, ist die theatrale Natur des Menschen:

In jener älteren Welt, die wir die mittelalterliche nennen, die aber in ihrer verjüngten Form, der des Barock, bis an die Schwelle des neunzehnten Jahrhunderts reichte, ja noch durch dieses hindurch, bis in unsere, der heute Lebenden, eigene Jugend, war alles ein Schauspiel: von der Vermählung des Fürsten bis zur Hinrichtung des Gewalttäters, von der Einholung fremder Gesandten bis zur alljährlich wiederkehrenden Kirchweih im kleinen Dorf. Manches hat sich von diesem Überreichtum an Aufzügen und Zeremonien da und dort in Europa gehalten, in den katholischen Ländern mehr als in den protestantischen. [...] Hier in Wien, im Schatten der Kaiserburg und des Stefansdomes, hat sich von diesen Feierlichkeiten am meisten gehalten, und unter einer ganz naiven, auf reiner Festfreude, reinem Theatersinn ruhenden Teilnahme der ganzen Bevölkerung. ${ }^{95}$

Reinhardt argumentiert strukturell gleichsinnig, wenn er behauptet, dass "[h]eute und für alle Zeiten [...] der Mensch im Mittelpunkt aller Schauspielkunst stehen [muß], der Mensch als Schauspieler ${ }^{96}{ }^{96}$ Interessant ist

93 Ebd., S. 171.

94 Reinhardt, Über ein Theater, wie es mir vorschwebt (wie Anm. 30), S. 75.

95 GW RA II, S. 325.

96 Max Reinhardt, Über die Bedeutung des Schauspielers. In: Max Reinhardt (wie Anm. 7), S. 423.

\section{Franz-Josef Deiters}


es zu sehen, wie ebendieses zirkuläre Zeichenmodell auch die zeitgenössische Philosophie prägt. Wenn etwa der Begründer der Philosophischen Anthropologie, Helmuth Plessner, in seinem Essay "Zur Anthropologie des Schauspielers" (1948) für seine Bestimmung der exzentrischen Positionalität des Menschen den Schauspieler zur paradigmatischen Figur erhebt

(Als das Verhältnis seiner selbst zu sich selbst ist er [der Schauspieler] die Person seiner Rolle, für sich und für den Zuschauer. In dieser Verhältnismäßigkeit wiederholen Spieler und Zuschauer jedoch nur die Abständigkeit des Menschen zu sich und zu einander, die ihr tägliches Leben durchdringt[. ${ }^{97}$ )

oder wenn Martin Heidegger in seiner Abhandlung "Der Ursprung des Kunstwerkes" (1935/36) vom "Dingcharakter des Werkes" spricht und davon, dass "[d]ie Kunstwerke [...] durchgängig, wenn auch in ganz verschiedener Weise, das Dinghafte" zeigen, ${ }^{98}$ dann erweist sich daran, wie genau sich Hofmannsthals und Reinhardts Bemühungen um eine Verweltlichung des Theaters in den zeitgenössischen semiologischen Diskurs einpassen.

Daraus erhellt, dass Hofmannsthals zirkulärem Zeichenmodell nicht nur eine zeitliche, sondern auch eine räumliche Dimension eignet. Wenn er in zeitlicher Hinsicht den Anschluss vor allem an vorklassische Theaterformen wie das mittelalterliche Mysterienspiel und das barocke Trauerspiel sucht, so macht bereits der Rekurs auf Ferdinand Raimund und Johann Nepomuk Nestroy sowie auf die höfischen Zeremonielle der Habsburger Monarchie deutlich, dass das Projekt einer Wiedereingliederung der Bühne in das weltliche Raum-Zeit-Kontinuum einen Vorgang der Verörtlichung des Theaters darstellt. Wenn Hofmannsthal nämlich 1922 in seinem "Wiener Brief $[I]$ « konstatiert, Wien sei "seit dem Ende des 18. Jahrhunderts - ja man kann, wenn man will, diese $\mathrm{Su}-$ prematie noch um achtzig Jahre zurückdatieren [...] [-] das theatralische Zentrum Deutschlands « ${ }^{99}$ gewesen, und wenn er in seinen "Gedanken über das Höhere Schauspiel in München« (1928) die Diagnose stellt, dass »[i]n München [...] das alte süddeutsche Theaterwesen fort[lebe],

97 Helmuth Plessner, Zur Anthropologie des Schauspielers. In: Ders., Gesammelte Schriften. Hg. von Günter Dux u.a. Bd. 7. Frankfurt a.M. 2003, S. 399-418, hier S. 411.

98 Martin Heidegger, Der Ursprung des Kunstwerkes. In: Ders., Gesamtausgabe. Hg. von Friedrich-Wilhelm von Herrmann. Bd. 5. Frankfurt a.M. 1977, S. 1-74, hier S. 25.

99 GW RA II, S. 272. 
das in Wien zwischen 1780 und 1830 seine Blüte gehabt« habe ${ }^{100}$, dann wird damit die lokale Situiertheit des Spiels als wesentlicher Zug eines weltlichen Theaters behauptet. In diesem Sinne spricht er »vom Ortsund vom Zeitgeist «101 des Theaters. Ebendiese raumzeitliche Verortung ist dem entweltlichten Theater der klassischen Episteme hingegen verloren gegangen; in seiner Verpflichtung auf die Schrift als Medium zur Repräsentation abstrakter Ideen produziert das Theater der klassischen Episteme Universalitätseffekte, die ihren Ort allein im distinkten, raumzeitlich ortlosen Zeichenraum der Schrift haben. Als solches ist das "höhere Bildungstheater «102 nicht im eigentlichen Sinne verortet, vielmehr hat es seinen Nichtort in der Hauptstadt des Deutschen Reiches, die ihm zur Chiffre wird:

In der jungen riesenhaften Großstadt und den weit älteren Städten mittleren Maßes stehen sich nicht etwa wie in Frankreich Provinz und Hauptstadt gegenüber, sondern die Antithese ist weit besonderer. Sie ist einzigartig, wie alles in der deutschen Situation. Berlin ist nicht die Hauptstadt - kein Münchener, kein Stuttgarter und kein Hamburger wird Berlin für seine Hauptstadt ansehen -, aber es ist die eine überwältigend große deutsche Stadt. Wer sie betritt, den umgibt mit einer Kraft, die nicht zurückzuweisen ist, - weniger ein Stadtwesen als eine Epoche. Das Heute, das Heute-Allein dominiert in ihr. ${ }^{103}$

Wenn Hofmannsthal von Berlin als einer Stadt spricht, die kein "Stadtwesen " besitze, der also der genius loci fehle, und wenn er notiert, dass in der "jungen riesenhaften Großstadt" »das Heute-Allein«, also die Traditionslosigkeit regiere, dann wird daran ersichtlich, warum Hofmannsthals und Reinhardts Projekt einer Überwindung des auf das entweltlichte und entweltlichende Schriftmedium verpflichteten Theaters zugunsten eines an der Instanz des leiblichen Schauspielers ausgerichteten weltlichen Theaters notwendig antimodernistische Tendenzen aufweisen muss. ${ }^{104}$

100 GW RA III, S. 180.

101 Ebd., S. 173.

102 Ebd., S. 180.

103 Ebd., S. 181f.

104 Deshalb ist es problematisch, wenn Benno Fleischmann in seinem Buch, dem ersten deutschsprachigen Buch über Max Reinhardt überhaupt, 1948 urteilt: »Reinhardt hat ohne jede dogmatische oder weltanschauliche Färbung seiner Schöpfung, ja ohne jedes über die unmittelbarste theatralische Forderung hinausgehende Programm tatsächlich Epoche gemacht« (Benno Fleischmann, Max Reinhardt. Die Wiedererweckung des Barocktheaters. Wien 1948, S. 10f.).

\section{Franz-Josef Deiters}


Eine Verweltlichung des Theaters kann es Hofmannsthals Argumentationsfigur zufolge in der modernen geschichtslosen Metropole, als deren Paradigma ihm Berlin gilt, nicht geben. Es sei daher, so Hofmannsthal, wichtig, dass sich die anderen deutschen Städte nicht in den Sog Berlins ziehen lassen, um ihrer vorgeblichen Provinzialität zu entkommen:

Provinziell wirkt vielmehr das unterscheidungslose Übernehmen der berlinischen Theatermode. Je mehr das Münchener Publikum von seinem ersten Theater fordert, je bestimmter es sich dem, was dort geleistet wird, wechselweise anschließt und widersetzt, desto sicherer werden sich die fühlen, denen die Leitung obliegt. Die riesenhafte Großstadt reißt an sich, experimentiert, verbraucht und wirft weg. Ein München, ein Hamburg, ein Wien müssen mit der Münze zahlen, die nur sie prägen und ausgeben: ein Theatergeist, an dem ein paar Jahrhunderte geformt haben; ein bestimmter Geschmack; eine beharrende Wärme, eine anhängliche Teilnahme. ${ }^{105}$

Entsprechend liest sich Hofmannsthals Erzählung von den Wandlungen des Theaters wie ein Gegenmodell zu Gottscheds teleologischer Erzählung vom Werden des Theaters zur entweltlichten Bühne der klassischen Episteme:

Das Theater ist von den weltlichen Institutionen die einzig überbliebene gewaltige und gemeingültige, die unsere Festfreude, Schaulust, Lachlust, Lust an Rührung, Spannung, Aufregung, Durchschütterung geradhin an den alten Festtrieb des alten ewigen Menschengeschlechtes bindet. [...] Auf der Nilbarke, die von Dorf zu Dorf glitt, erhob sich zu Pharaonenzeiten der Tisch mimender Gaukler; ihm aufs Haar glich das Gerüst, auf dem dreitausend Jahre später Pulcinella und Tabarin hervortraten. Zu Ende des siebzehnten Jahrhunderts kommen die italienischen »Masken« über die Alpen, Harlekin ihr Anführer. Nirgends wird ihnen so wohl wie in Wien. Hier wurzeln sie sich ein, und Harlekin aus Bergamo wird Hanswurst aus Salzburg. Aus Gozzis Hand empfing Raimund die burleske Masken- und Märchenwelt und setzte ihr ein wienerisches Herz ein. Unter Nestroys Fingern verändert sie sich; der Märchenhauch geht weg, aber die Gestalten, ob auch ein ätzendes Etwas ihre treuherzigen Mienen verschärft, es sind um so erkennbarer die ewigen Figuren des Mimus, es sind die Tröpfe und die Spötter, die Stupidi und die Derisores der antiken Komödie, es sind die Handwerker wie in Philistions und Theokrits uralten Possen: Knieriem, Leim und Zwirn, und Kilian der Färber, Knöpfel der Pfaidler, Weinberl der Kommis, und Christopherl der Lehrbub, - gewaltige Ahnenreihe, ewiges Leben! $!^{106}$

105 GW RA III, S. 182.

106 GW RA II, S. 269.

Max Reinhardts und Hugo von Hofmannsthals Theater der Stimmung 217 
In Hofmannsthals Perspektive gibt es, anders als bei Gottsched, keine Geschichte des Theaters im Sinne eines linear-aszendenten, teleologisch auf die Etablierung des Repräsentationsmodells ausgerichteten Geschehens, sondern ein Geschehen unendlicher proteischer Umbildungen, in denen die theatrale Natur des Menschen ihre je orts- und zeitspezifische leibliche Gestalt hervorbringt.

\section{$\mathrm{V}$}

Wenn aber genau diese Kette von durch den jeweiligen genius loci regierten Gestaltwerdungen des Theaters an dem traditionslosen Nichtort der modernen Metropole Berlin zerrissen ist, dann können Hofmannsthals und Reinhardts Bemühungen um eine Verweltlichung der Bühne im Berliner Zirkus Schumann, der von Hans Poelzig im Jahre 1918/19 zum Großen Schauspielhaus umgebauten ehemaligen Markthalle am Schiffbauerdamm, in der Wiener Rotunde, der Breslauer Jahrhunderthalle oder in der Londoner Olympiahalle nicht ihr Genügen finden. Es sind deshalb wohl theoriestrategische Gründe, die Hofmannsthal und Reinhardt einen Ort wie Salzburg für ihr größtes gemeinsames Projekt, die Salzburger Festspiele, wählen lassen. ${ }^{107}$ Denn, so konstatiert Max Reinhardt,

[s]elbst in jener leidenschaftlichen Arbeit, die sich durch die Aktivität eines Großstadttheaters ergab, ist das Wertvollste verlorengegangen: der Sinn für das Spiel, der in der Kindheit so stark war und auf den in der Kunst und insbesondere am Theater nicht verzichtet werden kann. [...] Ich stelle fest, daß die dramatischen Elemente, wie sie sich im alten österreichischen und bayrischen Theater finden - wie die Commedia dell'arte, die Aufführung

107 Wenn hier Reinhardt und Hofmannsthal als Begründer der Salzburger Festspiele genannt werden, so gilt dies in ästhetischer Hinsicht. In organisatorisch-institutioneller Hinsicht waren weitere Personen beteiligt. Norbert Christian Wolf führt aus: "Gegründet wurde die Salzburger Festspielhaus-Gemeinde am 1. August 1917 durch den Salzburger Kaufmann Friedrich Gehmacher und den Wiener Musikkritiker Heinrich Damisch [...]. Am 15. August 1918 wählte die Vollversammlung des Vereins Max Reinhardt, Richard Strauss und Franz Schalk in den neugegründeten Kunstrat. Hugo von Hofmannsthal stieg erst 1919 [...] in die konkrete Planung ein, nachdem der Kunstrat um ihn sowie Alfred Roller erweitert worden war" (Norbert Christian Wolf, Ordnungsutopie oder Welttheaterschwindel? Hofmannsthals Salzburger Festspielkonzepte in ihrem kultur- und ideologiegeschichtlichen Kontext. In: HJb 19, 2011, S. 217-254, hier S. 218); vgl. auch Die Salzburger Festspiele. Ihre Geschichte in Daten, Zeitzeugnissen und Bildern. Bd. 1. Hg. von Edda Fuhrich und Gisela Prossnitz. Salzburg 1990.

\section{Franz-Josef Deiters}


von Mysterienspielen, religiösen Werken, französischen, spanischen und italienischen Stücken -, und das musikalische Element des Theaters auf jener Bühne nicht genügend Nährboden finden. ${ }^{108}$

Sogar Wien, für das der österreichische Bühnenschriftsteller Leopold Jacobson noch wenige Jahre zuvor, 1905, in seiner Kritik des Gastspiels von Max Reinhardts Kleinem und Neuem Theater im Theater an der Wien die Traditionsverbundenheit als zentrales Differenzkriterium gegenüber der Berliner Experimentierfreude betont hatte, ${ }^{109}$ kommt aus Hofmannsthals Perspektive für das Festspielprojekt nicht mehr in Betracht. In seinem Essay »Das Salzburger Große Welttheater« von 1922 konstatiert er das Abreißen der Traditionsreihe auch für die österreichische Hauptstadt:

In einer sehr großen Stadt, wie Wien, aber ist so viel Neues und Fremdes zumal durch die Zeitungen ins Denken und Reden gedrungen, daß sich mit dem, was im Volk an altem naivem theatralischen Sinn noch da ist, kein "Publikum" ganz entscheidend mehr durchsetzen läßt - besonders seit die Schranken zwischen der »Stadt« mit ihren unvolksmäßigen Kunstanstalten und der »Vorstadt" gefallen sind. ${ }^{110}$

Ein dem genius loci verhaftetes, ihn zur Darstellung bringendes Theater ist allein außerhalb der metropolitanen Nichtorte möglich; und so entwirft Hofmannsthal 1921 ein weitgespanntes landschaftliches Traditionspanorama für die geplanten »Festspiele in Salzburg«:

Musikalisch theatralische Festspiele in Salzburg zu veranstalten, das heißt: uralt Lebendiges aufs neue lebendig machen; es heißt: an uralter sinnfällig auserlesener Stätte aufs neue tun, was dort allezeit getan wurde; es heißt: den Urtrieb des bayrisch-österreichischen Stammes gewähren lassen, und diesem Volk, in dem »die Gabe des Liedes, des Menschensachenspielens, des Holzschneidens, des Malens und des Tonsetzens fast allgemein verteilt ist«,

108 Max Reinhardt, Auf der Suche nach dem lebendigen Theater. In: Max Reinhardt (wie Anm. 7), S. 227-231, hier S. 227f.

109 "Je weiter das Gastspiel der Berliner fortschreitet, desto augenfälliger wird es, wie viel Natur und künstlerisches Temperament bei uns vorhanden ist, sieht man, was unser Besitz ist und was jenen mangelt, lernt man aber auch erkennen, was uns fehlt und jene in Fülle haben. Uns gehört die große schauspielerische Kultur, ihnen der starke Spürsinn nach neuen Theaterwerten und das literarische Ideal. Wir sind um die gewisse österreichische Idee zurück, haben die bedächtige Weiterentwicklung, jene haben das Experiment. Sie richten Säulen auf, um sie bedenkenlos morgen wieder einzureißen; wir aber konservieren «. Leopold Jacobson in: Neues Wiener Journal, 21. Mai 1905, zit. nach Ambivalenzen (wie Anm. 5), S. 47.

110 GW D III, S. 171f. 
den Weg zurück finden helfen zu seinem eigentlichen geistigen Element. [...] Es ist etwas in diesem Tun und Treiben, diesem unbesiegbaren Drang zur Darstellung, in dem Bild und Klang, pathetische Gebärde und Tanzrhythmus zusammenfließen, das an Attika gemahnt; und hier wie dort scheint es an das gleiche Naturgegebene gebunden: das Bergland. Ein Bergtal ist ein natürliches Theater, und sonderbar genug, der theatralische Trieb des südlichen deutschen Stammes folgt den Bergketten. So strahlt er bis in den Böhmerwald aus; die Passionsspiele zu Höritz sind sein letztes lebendiges Überbleibsel; so geht er nördlich bis Niederbayern, östlich bis an die ungarische Ebene. Die Nürnberger Landschaft gehört noch dazu, die Hügel von Bayreuth gehören dazu. Und sollte es Zufall sein, daß Wagner Bayreuth gewählt hat? In Bayreuth steht aus der Markgrafenzeit das prunkvolle Barocktheater, das ein süddeutscher Fürst geschaffen hat. Es ist nichts Zufall, alles geographische Wahrheit, tiefer Zusammenhang zwischen scheinbar nur Geistigem und scheinbar nur Physischem. ${ }^{111}$

Beansprucht wird für die projektierten Festspiele der Status, "uralt Lebendiges aufs neue lebendig [zu] machen«, also - im Sinne des zyklischen Zeichenmodells - ein Vorgängiges, den »theatralische[n] Trieb des südlichen deutschen Stammes", als eine Naturmacht sichtbar zu machen (»[e]in Bergtal ist ein natürliches Theater») und so den »tiefer[en] Zusammenhang zwischen scheinbar nur Geistigem und scheinbar nur Physischem« zu revidieren, auf dessen Unterscheidung das Repräsentationsmodell der klassischen Episteme beruht.

In seiner Lobrede auf »Eleonora Duse. Die Legende einer Wiener Woche" von 1892 wird ersichtlich, wie sehr die Orientierung am zyklischen Zeichenmodell Hofmannsthals Denken von Beginn an bestimmt. Dort heißt es:

Denn dazu, glaube ich, sind Künstler: daß alle Dinge, die durch ihre Seele hindurchgehen, einen Sinn und eine Seele empfangen. "Die Natur wollte wissen, wie sie aussah, und schuf sich Goethe." Und Goethes Seele hat widerspiegelnd tausend Dinge zum Leben erlöst. ${ }^{112}$

Die Figur der Rückkehr, die der autobiografische Aspekt von Max Reinhardts Begründung des Projektes der Salzburger Festspiele kennzeichnet, ist von analoger Struktur:

111 GW RA II, S. 264-266.

112 GW RA I, S. 478.

220 Franz-Josef Deiters 
wieder in meiner heimatlichen Landschaft, hatte ich den Wunsch, ein Theater dort aufzubauen, wo das Theater seinen Ursprung hat, auf österreichischbayrischem Boden, in der Stadt, in der meine Laufbahn begonnen hatte. Hier gibt es wirkliche Volkspoesie (Oberammergau, Zell am See usw.), und diese Poesie existiert nicht in Büchern, um nur beim Lesen lebendig zu werden, sondern sie ist aus der Freude am Spiel entsprungen, und nur durch sie kann das wahre Theater entstehen.

Salzburg ist wegen seiner Lage, seiner Architektur, seiner früheren Geschichte, wegen Mozart, wegen der großen Intelligenz und der Unabhängigkeit der kirchlichen Kreise, die hier regierten und infolgedessen immer viel Einfluß gehabt haben, der natürliche Ort für dieses Theater. [...] So war es ein selbstverständlicher Gedanke, dort ein Theater zu begründen, [...] das auf Grundlagen aufgebaut sein würde, die anders sind als diejenigen, unter denen ein Theaterunternehmen in einer Großstadt leidet [...].

Der Grundgedanke war: das Theaterspiel sollte wieder ein Fest werden, wie es in der Antike und im Mittelalter unter Führung der Kirche gewesen war [...]. Aus meinem ersten Jahr im Salzburger Theater erinnerte ich mich an den wundervollen Park von Hellbrunn, und ich wandte mich an den Kaiser Franz Joseph mit der Bitte, den Park für die Errichtung eines Festspielhauses zur Verfügung zu stellen. ${ }^{113}$

Ausgehend von der semiologischen Grundorientierung von Reinhardts und Hofmannsthals Äußerungen, wird schließlich klar, warum die Errichtung eines Festspielhauses in Hellbrunn, für das Hans Poelzig die Entwürfe lieferte, nicht die Ultima Ratio für das von ihnen verfolgte Projekt eines weltlichen oder, in Reinhardts Diktion, eines "lebendigen" Theaters sein konnte. Schon 1924 urteilt er in "Auf der Suche nach dem lebendigen Theater«:

Poelzigs Projekt verzögerte sich durch die Schwierigkeiten, die erforderlichen finanziellen Mittel zu erhalten, die heutzutage erforderlich sind, um einen solchen Bau zu errichten. Und doch hat es sich als glücklich erwiesen, daß das Projekt nicht sofort ausgeführt werden konnte, weil sich erst während dieser Periode des praktischen Experiments der Festspielgedanke vollständig und klar herauskristallisierte. [...] Für die Aufführung von Mysterienspielen wird ein barockes, phantastisches Theatergebäude, wie es Poelzigs erstes Projekt vorsah, nicht benötigt, sondern ein ernstes, heiliges Interieur, wie in einer Kathedrale. Das Pathos der Höhe. Kein umfangreicher Mechanismus für die Bühnentechnik. ${ }^{114}$

113 Reinhardt, Auf der Suche nach dem lebendigen Theater (wie Anm. 108), S. 228.

114 Ebd., S. 231.

Max Reinhardts und Hugo von Hofmannsthals Theater der Stimmung 221 
Reinhardts Bemerkungen reflektieren seine Erkenntnis, dass das Monofunktionsgebäude Schauspielhaus - ungeachtet seiner konkreten architektonischen Ausgestaltung - als ein Relikt des Repräsentationsmodells die Verweltlichung der Bühne blockiert, da es den Ort des Spiels aus dem weltlichen Raum-Zeit-Kontinuum ausgliedert. Um es wirklich zu verorten, muss das Theaterspiel in das weltliche Raum-Zeit-Kontinuum eingebunden und an Orte wie den Platz vor dem Dom, wo er 1920 erstmals den "Jedermann" inszeniert, oder die Kollegienkirche verlegt werden, wo er 1922 das »Salzburger Große Welttheater« zur Aufführung bringt. Reinhardt begründet die Wahl dieser `Naturschauplätze für die Festspiele wie folgt:

Jeder Platz, jede Straße hier scheint ja von vornherein zum Schauplatz eines Spieles geschaffen zu sein. Die Atmosphäre von Salzburg ist durchdrungen von Schönheit, Spiel und Kunst. Von den alten Mysterienspielen des Mittelalters führt eine dauernde Kette von Schaustellungen und Spielen bis in unsere Zeit. Das Heckentheater in Mirabell, das Steintheater in Hellbrunn, in dem 1617 die erste deutsche Oper aufgeführt wurde, sind nur Glieder dieser Reihe. ${ }^{115}$

Mittels der Verlegung des Theaterspiels an diese `Naturschauplätzer soll im Sinne des zyklischen Zeichenmodells die Theatralik der süddeutschen Kulturlandschaft sichtbar gemacht werden. In diesem Sinne behauptet Max Reinhardt: »Die Schauspielkunst ist eine Kunst der Enthüllung, nicht der Verwandlung!«116 Mögliche Einwände gegen das Konzept vorwegnehmend, stellt Hofmannsthal genau diesen Aspekt explizit heraus, wenn er anmerkt, dass ein

Programm, das ein Schillersches Drama oder Goethes »Faust« und daneben die Oper "Ariadne«, ein Mysterienspiel und "Die Fledermaus" umspannt, $[\ldots]$ leicht als unzusammenhängend, der bindenden Idee entbehrend erscheinen [könnte], sogar als platt opportunistisch: nur veranstaltet, um vielerlei Geschmacksrichtungen zu befriedigen, ohne höheren zusammenhaltenden Gedanken. Dennoch ist ein solcher Gedanke vorhanden: den süddeutschen (bayrisch-österreichischen) Theatergeist anschaulich zu machen, indem man theatralische Werke der verschiedensten Sphären vors Publikum bringt,

115 Max Reinhardt, Festliche Spiele. Ein Gespräch mit Max Reinhardt. In: Max Reinhardt (wie Anm. 7), S. 241-244, hier S. 242.

116 Reinhardt, Der Schauspieler und seine Rolle (wie Anm. 61), S. 423.

222 Franz-Josef Deiters 
deren Gemeinsames in der gemeinsamen Abstammung vom älteren süddeutschen Theaterwesen liegt: gleichsam Kinder einer Familie. ${ }^{117}$

Bei der Suche nach Bühnenstücken, die dieser Theaterkonzeption entsprechen, bemühen sich Reinhardt und Hofmannsthal um die Zusammenstellung eines Kanons, der die Funktion eines gestischen Leibes des örtlichen genius loci zu erfüllen vermag. In "Auf der Suche nach dem lebendigen Theater « führt Reinhardt aus, dass er »die vorhandene Volksliteratur und viele Mysterienspiele [studierte], die noch in der Umgebung Salzburgs existieren oder von einzelnen Personen gesammelt worden sind «. ${ }^{118}$ Hofmannsthal sei in diesem Zusammenhang die Aufgabe zugefallen, »das vorhandene reiche Material für unsere Zeit zum Leben zu erwecken, es zu überarbeiten und den vorhandenen Möglichkeiten, den Schauspielern und den Örtlichkeiten, anzupassen «119. Als Kernstück dieses Kanons kristallisiert sich sehr bald der "Jedermann" heraus, von dem Hofmannsthal meint, dass "[d]ramatische Gebilde dieser großen simplen Art [...] wahrhaftig aus dem Volk hervorgestiegen" und als solche "wiederum vor das Volk «120 zu bringen seien. Reinhardt seinerseits reflektiert das Regiekonzept zum "Jedermann", das er als einen Vorgang der Einbettung des Spiels in die Gegebenheiten des Ortes und also als eine Operation zur Verweltlichung der Bühne beschreibt:

Eine Bretterbühne vor den Türen des Doms. Herolde, die das Spiel ankündigten. Auftritt der Schauspieler von den benachbarten Plätzen aus. Die Glocken aller Kirchen läuten. Geheimnisvolle Rufe von den Kirchtürmen, herab von der Festung und aus größerer Entfernung, die den Jedermann zum Tode rufen. Der Teufel, der aus den Zuschauerreihen auf das Podium springt. Der Glaube und der Engel, die am Ende aus dem Dom heraustreten. Die breiten Plätze der Stadt angefüllt mit einer dichten Zuschauermenge. An

117 GW RA III, S. 178.

118 Reinhardt, Auf der Suche nach dem lebendigen Theater (wie Anm. 108), S. 229. Reinhardt selbst inszenierte, wie Hugo Fetting berichtet, neben dem "Jedermann" (1920-1937, mit Ausnahme der Jahre 1922-1925) und dem "Salzburger Großen Welttheater" (1922-1925) Molières »Der eingebildete Kranke« (1923), »Das Mirakel" von Karl Vollmoeller (1925), Hofmannsthals »Die grüne Flöte« (1925), Carlo Gozzis »Prinzessin Turandot« (1926), "Der Diener zweier Herren" von Carlo Goldoni (1926 und 1930), William Shakespeares "Ein Sommernachtstraum" (1927 und 1930), Friedrich Schillers "Kabale und Liebe" (1927 und 1930) und "Die Räuber" (1930), Somerset Maughams »Victoria« (1930), Hofmannsthals »Der Schwierige" (1931), Johann Wolfgang Goethes "Stella« (1931) sowie den ersten Teil seines "Faust« (1933-1937). Hugo Fetting in: Max Reinhardt (wie Anm. 7), S. 214.

119 Reinhardt, Auf der Suche nach dem lebendigen Theater (wie Anm. 108), S. 229.

120 GW D III, S. 105. 
den Fenstern des benachbarten Klosters Mönche und Priester, in der ersten Reihe der Erzbischof und das Domkapitel. Der Verkehr ruht völlig, die gesamte Stadt lauscht und schaut atemlos zu. Ein wunderbares Lichterspiel: zunächst Tageslicht, dann Sonnenuntergang, schließlich Fackeln. ${ }^{121}$

Reinhardt legt den Fokus auf die intendierte Entgrenzung von Spiel und Welt: Die Schauspieler treten "von den benachbarten Plätzen aus" auf; ihr Spiel ist also nicht auf die "Bretterbühne vor den Türen des Doms" eingegrenzt. "Glocken aller Kirchen«, welche die Gläubigen zum Gottesdienst rufen und also nicht eigentlich Bestandteil des Spiels sind, tragen trotzdem zum Gesamteindruck der Inszenierung bei; "Kirchtürme[]" und die "Festung" spielen gleichermaßen mit. Die Figuren "Glaube« und "Engel" treten "aus dem Dom" heraus und gewinnen so den Nimbus von Verkörperungen der in der Welt wirkenden Mächte. Der Teufel springt als eine weitere in der Welt wirksame Macht »aus den $\mathrm{Zu}$ schauerreihen auf das Podium«. Das Auditorium ist nicht auf die Plätze der Zuschauerreihen begrenzt, sondern diffundiert ins Umland zu den "Fenstern des benachbarten Klosters". Schließlich tragen die tageszeitlich wechselnden Lichtverhältnisse mit dem Wechsel von »Tageslicht«, "Sonnenuntergang" und das nächtliche Dunkel erhellendem Fackellicht zur intendierten Entdifferenzierung von Spiel und Welt bei. Das Spiel wird, so das Programm, zur Veranschaulichung des weltlichen Sterbens eines reichen Mannes, den die Zuschauer als einen Menschen aus ihrer eigenen Mitte erkennen sollen.

Sind Reinhardts Ausführungen im Tone eines die Realisierung antizipierenden Regiekonzepts vorgetragen, so behauptet Hofmannsthal gar dessen Erfolg, wenn er sich in "Das alte Spiel von Jedermann" (1911) zum Metazuschauer stilisiert, der ex post die tatsächliche Wirkung des Spiels auf das Publikum beschreibt:

Diese Arbeit aber beendigt, durch ähnliche verstehende und teilnehmende Aussprüche erfreut, war es ein leichtes, völlig zurück- und gegenüberzutreten, als ein Zuschauer unter Zuschauern das lebendige Spiel auf sich wirken zu lassen, dessen Eindruck durch diese Blätter festzuhalten versucht wird. Glocken wurden geläutet, kräftig und anhaltend. Da wurde die ganze große Masse still und es war, als fühlte man das Stillwerden jedes einzelnen. Indessen war es auch ganz dunkel geworden. In dem riesigen, kaum erleuchte-

121 Reinhardt, Auf der Suche nach dem lebendigen Theater (wie Anm. 108), S. 229.

224 Franz-Josef Deiters 
ten Raum wurde aus den Tausenden von zufällig zusammengekommenen Menschen, deren Gesichter das einzige Helle in dem dämmrigen Dunkel waren, mit einem Schlag ein Wesen: die Menge. Vor diese Menge trat nun der Spielansager oder Herold und sagte das Spiel an. Er trat seitwärts auf dem Gerüst heraus, ging nach vorne und stieg ein paar Stufen empor, die am vordersten, niedrigsten Teil des Gerüstes zu den mittleren höheren hinaufführten. Hier blieb er stehen, genau in der Mitte, und sagte seinen Spruch her. Von oben fiel ein Schein auf ihn und erleuchtete sein buntes Heroldsgewand, seine Hand mit dem weißen Stab, sein Gesicht, das gewöhnlich war, und über dem ein Kopfschmuck mit recht bunten und schönen Straußenfedern den Kopf des Mannes ansehnlich machte. Als er geendet hatte, war die Menge minder ruhig als vorher: es schien, als sei eine ganz besonders wunderbare Spannung von ihr genommen, die während des Glockenläutens auf ihr gelegen hatte. [...] Einen Augenblick lang war es völlig dunkel, dann fiel taghelles Licht auf das unterste Gerüst und auf den Schauplatz, der vor dem Gerüste lag. Das Gerüst und der Schauplatz waren leer. Sogleich geriet die Menge in eine kleine Unruhe, weil sie nun nicht wußte, wie das Spiel weitergehen würde und was sie sich erwarten sollte. Da kam der Schauspieler, welcher in dem Spiel den Jedermann vorstellte, mit schnellen Schritten auf das Gerüst zu, stieg hinauf, stand breitbeinig inmitten und wandte sein Gesicht der großen Menge zu. Sogleich wurden die Leute stiller, denn es war einer von den seltenen Schauspielern, welche eine große Gewalt über die Menge ausüben, je leichter, je mehr Leute sie vor sich haben. Diesem sah man es an, daß der Anblick einer so übergroßen Menge ihn reizte und befeuerte. [...] Da wurde der großen Menge gleich behaglich, wie sie den hübschen und reichen Mann da in der Mitte stehen sah, der sich seines Hauses und aller seiner Besitztümer so sehr freute und einen vollen Beutel Goldes in der Hand hatte. [...] Das alles hören die vielen tausend Zuhörer mit ihm, aber die mit ihm an seiner Tafel sitzen, hören nichts und begreifen sein Gebaren nicht, bis mit eins der Tod mitten unter ihnen steht und von hinten her seine grünlich fahle Hand auf Jedermanns Herz legt. ${ }^{122}$

Im auktorialen Gestus zeichnet Hofmannsthal die Wirkung des Spiels auf das Publikum als ein vollständiges Gelingen der intendierten stimmungshaften Transformation der Zuschauer zur entindividuierten "Menge«, und wenn er die »schnellen Schritte[] « und das »breitbeinig[e] « Stehen des Jedermann-Darstellers hervorhebt, stellt er den Rezeptionsvorgang als ein wesentlich von Sinneseindrücken bestimmtes Geschehen dar. Wie bei Reinhardt spielen die Licht- und Raumverhältnisse eine atmosphärisch zentrale Rolle. Vor allem aber wird der direkte Kon-

122 GW D III, S. 93-100.

Max Reinhardts und Hugo von Hofmannsthals Theater der Stimmung 225 
takt zwischen Darsteller und Publikum betont (»Diesem sah man es an, daß der Anblick einer so übergroßen Menge ihn reizte und befeuerte.«); ja es wird die Gemeinschaft der »Jedermann«-Figur mit den Zuschauern behauptet, wenn Hofmannsthal bemerkt, dass »die vielen Tausend Zuhörer« mit Jedermann die Rufe des Todes vernehmen, während die anderen Bühnenfiguren sie nicht hören können. Die ontologische Differenz von Schauspieler und dramatischer Figur wird damit verwischt und der Zuschauer in die Position des Zeugen eines realweltlichen Ereignisses versetzt. In Hofmannsthals Zeichnung des Wirkungsgeschehens ist mithin die Eingliederung des Spiels ins weltliche Raum-Zeit-Kontinuum erfolgreich vollzogen und die seit Reinhardts und Hofmannsthals ersten Spielen mit der Rampe intendierte Abkehr von der Guckkastenbühne des Repräsentationstheaters als geglückt behauptet.

Den gelungenen Wiederanschluss an die Tradition des dem zyklischen Zeichenkonzept der Ähnlichkeiten verpflichteten Volkstheaters reklamiert Reinhardt schließlich, wenn er für seine Salzburger »Jedermann«Inszenierung konstatiert, dass die lokale Bevölkerung in ihr den verschütteten genius loci erkannt habe:

Das Ergebnis war, daß nicht nur viele Freunde kamen, um das Spiel zu sehen, sondern daß die ganze Landbevölkerung aus der Umgebung herbeiströmte und in die Stadt drängte. Und vor allem: im folgenden Jahr wurde Hofmannsthals altes Mysterienspiel an vielen Orten aufgeführt. Besonders gute Vorstellungen fanden in Mondsee, Zell am See und in anderen ländlichen Gemeinden statt. Im Jahr darauf wurde das Spiel mit einer Volksmenge wiederholt. Ein Volkspoet schrieb es in einer Dialektform und reiste mit seiner Truppe damit herum. ${ }^{123}$

\section{VI}

Das Gelingen von Reinhardts und Hofmannsthals Projekt einer Verweltlichung der Bühne ist jedoch an die Stichhaltigkeit der starken epistemologischen Aussagen geknüpft, die ihr zyklisches Zeichenmodell impliziert. Denn das Theatermodell von entgrenzten Festspielen, die aus der lokalen Kultur erwachsen und ihren genius loci vergegenwärtigen,

${ }^{123}$ Reinhardt, Auf der Suche nach dem lebendigen Theater (wie Anm. 108), S. 229 f.

226 Franz-Josef Deiters 
behauptet die Überwindung der Desemiotisierung der phänomenalen Welt, die Michel Foucault als das wesentliche Kennzeichen der klassischen Episteme identifiziert hat. ${ }^{124}$ Genau eine solche Resemiotisierung der phänomenalen Welt erstreben all diejenigen, die in phänomenologischer Grundorientierung die Wissensordnung in der phänomenalen Welt zu verankern streben. Kritisch gegenüber diesen Versuchen, die auf positivistischen Fehlschlüssen beruhen, sei hier behauptet, dass ihnen auch Reinhardts und Hofmannsthals Festspielkonzept erliegt. Dieses erwächst nämlich nicht aus dem landschaftlichen Boden; vielmehr entspringt der behauptete genius loci der ästhetischen Wahrnehmung, das heißt einem Akt der entweltlichenden Bildproduktion, der die räumliche Umgebung zum entpragmatisierten Landschaftsbild stillstellt. Diese ästhetische Wahrnehmung setzt die das Subjekt-Objekt-Verhältnis konstituierende Desemiotisierung der phänomenalen Welt nämlich immer schon voraus. Überwinden lässt sich die Subjekt-Objekt-Spaltung nur subjektiv und auf Zeit: im ästhetischen Modus der Stimmung. Deren Rahmen aber wird durch Reinhardt und Hofmannsthal gesetzt. Es handelt sich mithin um Bilder der Idee der Wiedereingliederung des Bühnenraums in das weltliche Raum-Zeit-Kontinuum, um Bilder der Idee eines ungebrochenen Traditionszusammenhangs, um Bilder der Idee eines genius loci, die Hofmannsthal und Reinhardt durch wohlkalkulierte Techniken produzieren. Zur Bezeichnung des Ensembles dieser Techniken ließe sich von einer Grammatik der Verweltlichung der Bühne sprechen. Dies erweist sich schon daran, dass die Festspiele selber einen institutionellen Rahmen darstellen, in dem sich nicht eine lokale Gemeinschaft rituell vor sich selbst bringt, sondern der in Programmen, Ankündigungszetteln und Presseorganen international einer anonymen Öffentlichkeit angekündigt wird. In einem Brief an Heinz Herald vom 8. Juli 1927 weist Reinhardt selbst darauf hin, dass die Aufführungen des "Jedermann« "von den Gästen, den Ausländern, immer wieder begehrt, besucht und gepriesen worden ${ }^{125}$ seien. Auch die Nennung der Schauspielernamen in den Programmen zeigt die Persistenz der ontologischen Differenz der Ebenen von Darsteller und dramatischer Figur und also die Persistenz des Repräsentationsmodells an. Wie sehr die Setzung ei-

124 Vgl. Foucault, Ordnung der Dinge (wie Anm. 3).

125 Max Reinhardt [An Heinz Herald], Beauvallon, 8. Juli 1927. In: Max Reinhardt (wie Anm. 7), S. 233-238, hier S. 234. 
nes das Theaterspiel entweltlichenden Rahmens als konstitutiv für das Konzept der Salzburger Festspiele ist, verraten Äußerungen der beiden Festspielurheber selbst. So richtet Max Reinhardt an den Fürsterzbischof von Salzburg Ignatius Rieder am 16. Juli 1920 eine vielsagende Bitte:

Das einzige Bedenken dagegen, dieses Werk, das ursprünglich auf öffentlichen Plätzen und immer vor einer Kirche gespielt wurde, auf diesem ganz besonders dafür geeigneten Platze aufzuführen, liegt eben in diesem Glokkenläuten der benachbarten Kirchen, wodurch jedes gesprochene Wort unverständlich werden müßte. ${ }^{126}$

Es geht Reinhardt in seinem Bittschreiben eindeutig um die Ausschließung von störenden Geräuschen aus der unmittelbaren Umgebung, die keineswegs als dem Gelingen des Theaterspiels zuträgliche Anwesenheit eines genius loci erachtet werden. Vielmehr handelt es sich um eine Operation der Ausgliederung des Spielortes aus dem weltlichen RaumZeit-Kontinuum, wie sie mit der Errichtung von monofunktionalen Theatergebäuden betrieben wird. Zwar ist der ausgegliederte Raum nicht architektonisch realisiert und stellt keinen Rückzug aus dem Stadtraum dar, vielmehr greift das Theaterspiel expansiv auf den Stadtraum aus, den es okkasionell und ausschnittsweise als entweltlichten ästhetischen Raum beansprucht. Die Geste der Ausgliederung, die Reinhardts Bittzeilen um das Aussetzen des rituellen Glockenläutens der umliegenden Kirchen - und mithin des genius loci - ersichtlich wird, betont also die Kontinuität der Entweltlichung der Bühne.

Gleiches gilt für Hofmannsthals Bittschreiben an den Fürsterzbischof Rieder, das um die Erlaubnis zur Aufführung des "Salzburger Großen Welttheaters" in der Kollegienkirche als dem Gelingen der Inszenierung bestzuträglichen Ort nachsucht:

Aber er hat mir dies gesagt: ein Stück aufbauen im Freien wie dies Stück aufgebaut werden muß, in dreiwöchentlichen Proben, jede Gebärde, jede Betonung, und bei all diesen Proben und dann bei den Aufführungen der Nervenspannung und Angst vor dem Wetter ausgesetzt sein, immer die Regenwolke heraufziehen oder dahängen zu sehen - dem fühlt er sich und die Schauspieler nicht gewachsen. Es liegt in der Sache selbst, wie in jeder künstlerischen viel Anspannung, ja Angst und Beklemmung - da darf nicht noch

${ }^{126}$ Max Reinhardt, An den Fürsterzbischof von Salzburg Ignaz Rieder, 16. Juli 1920, Schloß Leopoldskron bei Salzburg. In: Max Reinhardt (wie Anm. 7), S. 226f., hier S. 226.

228 Franz-Josef Deiters 
von Außen etwas ganz Ängstigendes dazu treten. [...] Dann kommt aber noch eines dazu: das Welttheater braucht schöne, alte, würdige Musik, Chöre, Bläser, und vor allem die Orgel, fast wie ein Oratorium muß Musik darin sein - wo könnte das so schön klingen, ja wo soll man überhaupt, außer in der Kirche und am Domplatz, dies ermöglichen? ${ }^{127}$

Die Klage über die nicht zu kalkulierenden Einflüsse des »Wetter[s]《 als "Angst und Beklemmung « auslösende Störfaktoren signalisiert deutlich den Wunsch nach einem aus der Welt ausgegliederten Spielort. Gleiches gilt für den Hinweis auf die »dreiwöchentlichen Proben«, in denen »jede Gebärde, jede Betonung « einstudiert und mithin das Anästhesieren der Schauspielerpersönlichkeit geübt werde; auch sie widersprechen dem Theorem von der Bedeutung der Schauspielerpersönlichkeit und vom Spiel als dem gestischen Leib des genius loci fundamental. Es geht also bei der Vorbereitung der Festspiele durchgängig um Operationen der Grenzziehung - und nicht um solche der Entgrenzung.

Dass auf der Bühne die abstrakte Idee des genius loci repräsentiert wird, ist auch daran ersichtlich, dass Hofmannsthal den "Jedermann" als ein "menschliches Märchen [...] in christlichem Gewande «128 charakterisiert, das heißt Form und Inhalt scheidet und damit das Stück als ein ästhetisches Gebilde und nicht als rituelles Medium identifiziert. Dies aber setzt seine Entzauberung voraus:

Sein eigentlicher Kern offenbarte sich immer mehr als menschlich absolut, keiner bestimmten Zeit angehörig, nicht einmal mit dem christlichen Dogma unlöslich verbunden: nur daß dem Menschen ein unbedingtes Streben nach dem Höheren, Höchsten dann entscheidend zu Hilfe kommen muß, wenn sich alle irdischen Treu- und Besitzverhältnisse als scheinhaft und löslich erweisen, ist hier in allegorisch-dramatische Form gebracht, und was gäbe es Näheres auch für uns? Denn wir sind in der Enge und im Dunkeln, in anderer Weise als der mittelalterliche Mensch, aber nicht in minderem Grade; wir überschauen vieles, durchblicken manches, und doch ist die eigentliche Seelenkraft des Blickens schwach in uns; vieles ist uns zu Gebote, aber wir sind keine Gebieter; was wir besitzen sollten, das besitzt uns, und was das Mittel aller Mittel ist, das Geld, wird uns in dämonischer Verkehrtheit zum Zweck der Zwecke. ${ }^{129}$

127 Hugo von Hofmannsthal, Brief an Fürsterzbischof Ignatius Rieder (Rodaun) vom 6. Februar 1922, zit. nach Ambivalenzen (wie Anm. 5), S. 86 (Hervorh. im Orig.).

128 GW D III, S. 106.

129 Ebd., S. 90.

Max Reinhardts und Hugo von Hofmannsthals Theater der Stimmung 229 
Hofmannsthal diagnostiziert hier nicht nur die verkehrten Zeitverhältnisse im Anschluss an Georg Simmels »Philosophie des Geldes« (1900); die den Modernetheorien à la Simmel eigene kritische Selbstreflexion der subjektphilosophischen Grundannahmen setzt jedoch selbst die Entweltlichung der Bühne voraus, welche die klassische Episteme kennzeichnet. In diesem Sinne offenbart auch Hofmannsthals Kritik am Repräsentationstheater die Persistenz jenes Zeichenregimes, das er zu überwinden trachtet. In der Folge verwandelt sich die mittelalterliche Allegorie, die Hofmannsthal aufnimmt, weil sie noch diesseits der neuzeitlichen Subjekt-Objekt-Spaltung liegt und von den zentralen Dichotomien innen/ außen, sinnlich/intelligibel nicht gesteuert wird, in eine neuzeitliche $\mathrm{Pa}-$ rabel, das heißt ein allgemeines Modell, eine Form, die eine Idee sinnlich darstellt und also von den Dichotomien innen/außen und sinnlich/intelligibel gesteuert wird. Allenfalls momenthaft kann mittels der Produktion von Stimmungseffekten die Formierung einer entindividuierten, alle weltlichen Distinktionen außer Kraft setzenden Menge gelingen. Nach Abschluss der Aufführung zerfällt sie wieder in die den Imperativen der Moderne gehorchenden Einzelnen. Die von Hofmannsthal formulierte Hoffnung, "gebrochenen Zuständen ein ungebrochenes Weltverhältnis gegenüberzustellen, das doch in der innersten Wesenheit mit jenem identisch ist «, ${ }^{130}$ also den verschütteten genius loci im Spiel sichtbar werden zu lassen, gelingt Hofmannsthal und Reinhardt nicht. Vielmehr bleibt das Festspieltheater Autorentheater.

Reinhardt ist das Scheitern des Festspielprojektes durchaus bewusst geworden, ${ }^{131}$ wenn er im Gestus der Resignation bekundet:

Eines Tages werde ich die Festspiele wahrscheinlich über haben und sie mich - vielleicht balde, ach balde. Das, was mich anzog, verliert sich, ist eigentlich nicht da. [...] Es bleibt etwas Farbiges, Buntes, Glänzendes, Drängendes, Schäumendes - aber so gut es mir noch oft schmeckt - ich möchte es nicht immer trinken. Es ist auch zu anstrengend, um wirklich festlich zu sein. Das Ganze ist aber eines von den vielen prächtigen Kleidern des Lebens, das man eben richtig getragen haben muß. Eine hübsche Form des Theaters, nicht mehr. ${ }^{132}$

130 Ebd., S. 106.

${ }^{131} \mathrm{Zu}$ Hofmannsthals Bewusstsein des Scheiterns vgl. Deiters, Auf dem Schauplatz des "Volkes" (wie Anm. 86), S. 206-208.

132 Max Reinhardt, Brief an Helene Thimig [1926], zit. nach Ambivalenzen (wie Anm. 5), S. 94 .

230 Franz-Josef Deiters 
Ja, er bekundet sogar, dass er sich die »Erfüllung« seiner »Idee in Gänze [...] von Amerika" erhoffe, ${ }^{133}$ mithin jenem paradigmatischen Nichtort, der hinsichtlich seiner posttraditionalen Modernität die von Reinhardt und Hofmannsthal gemiedenen Metropolen Berlin und Wien in den Schatten stellt. Selbst auf die Gefahr hin, dem Zynismus zu erliegen, muss daher wohl gesagt werden, dass es nicht allein das nationalsozialistische Regime gewesen ist, das Reinhardt schließlich nach Amerika getrieben hat; in gewisser Weise stellt der Weg nach Amerika den theoriestrategisch entelechischen Ort von Reinhardts und Hofmannsthals Festspielkonzept dar. »Die Erfüllung meiner Idee in Gänze erwarte ich mir von Amerika«: Diese Zeilen richtet Reinhardt schon am 21. Januar 1913 an den deutsch-amerikanischen Bankier und Mäzen der Metropolitan Opera Otto H. Kahn. In diesem Brief heißt es weiter:

Es unterliegt keinem Zweifel, daß Amerika wie kein anderes Land der geeignete Boden für die neue große Theaterform zu sein scheint. Amerika ist reif für dieses Projekt: es hat auf allen Gebieten des praktischen Kulturlebens Europa eingeholt, zum großen Teil auch überflügelt; es hat auch auf dem Gebiete der Kunst Großartiges geschaffen, sowohl organisatorisch wie schöpferisch; es hat Maler von Weltruf; es hat auf dem Gebiete der Musik die besten Konzerte und das beste Publikum dafür. Es besitzt sogar die erste Oper der Welt. - Sollte es gerade auf dem Gebiete des Theaters hinter den Leistungen der andern und seinen eigenen Leistungen auf anderen Gebieten zurückstehen?

Den Heißhunger danach spürt man aus vielen Symptomen und höchst merkwürdigerweise liegen diese Symptome (denken Sie z.B. an die Versuche, Freilichttheater zu schaffen) fast auf demselben Weg, auf dem auch unser Projekt das erste große Ziel bedeutet. ${ }^{134}$

Reinhardts und Hofmannsthals Festspieltheater bringt mithin nicht den genius loci der süddeutschen Kultur zur Erscheinung, vielmehr repräsentiert es die Sehnsucht der dem Repräsentationsparadigma nicht entkommenden posttraditionalen Moderne nach den (vermeintlichen) Sicherheiten einer traditionalen Vergangenheit. Diese traditionale Vergangenheit ist eine Idee, welche die posttraditionale Moderne allererst hervorbringt. ${ }^{135}$

133 Max Reinhardt [An Otto H. Kahn], Deutsches Theater zu Berlin, den 21. Januar 1913. In: Max Reinhardt (wie Anm. 7), S. 191-193, hier S. 192.

134 Ebd.

135 Mit ideologiekritischem Impetus hat Norbert Christian Wolf deshalb mit Recht von Hofmannsthals "rückwärtsgewandte[r] Ordnungsutopie« gesprochen. Wolf, Ordnungsutopie (wie Anm. 107), S. 221.

Max Reinhardts und Hugo von Hofmannsthals Theater der Stimmung 231 
